\title{
ENTENDIENDO LA TRATA DE SERES HUMANOS. A PROPÓSITO DE LAS LEGISLACIONES ESPAÑOLA, COLOMBIANA Y PERUANA
}

\author{
UNDERSTANDING TRAFFICKING IN HUMAN \\ BEINGS. REGARDING SPANISH, COLOMBIAN \\ AND PERUVIAN LEGISLATION
}

Angélica María Castro Acosta*

\section{Resumen}

La trata de seres humanos se erige como la nueva forma de esclavitud del siglo XXI, porque vulnera los derechos de los individuos, atenta contra la dignidad humana de quienes la sufren y constituye una forma de grave cosificación y explotación del ser humano por sus congéneres, en pos de beneficios económicos o de cualquier otra índole. Los estados se han esforzado por contenerla pero no han conseguido erradicarla, ello solo se puede lograr con educación, sensibilización y empoderando a las posibles víctimas. El presente artículo se ocupa, en primer lugar, sobre cuál es la denominación más comprensiva de los diferentes estadios biológicos del hombre, en orden a conseguir su protección plena en cualquier derecho nacional sin importar cuál sea su concepto legal de persona; y, en segundo lugar, propone una definición actual que, teniendo en cuenta las fórmulas contenidas en instrumentos jurídicos relevantes, resulte aplicable, se mantenga vigente y elimine las zonas grises.

\section{Palabras claves}

Delitos, derechos humanos, esclavitud, Protocolo de Palermo, trata de seres humanos.

\begin{abstract}
Trafficking in human beings stands as the new form of slavery of the XXI century, violates the rights of individuals, undermines the human dignity of those who suffer it and constitutes a form of serious reification and exploitation of human beings by their fellow human beings, for economic benefits or of any other kind. States have endeavored to contain it but
\end{abstract}

\footnotetext{
Abogada de la Universidad de la Sabana (Colombia), Licenciada en derecho de la Universidad de Zaragoza (España) y Abogada de la Universidad Mayor de San Marcos (Perú). Especialista en Derecho Procesal Civil de la Universidad Pontificia Bolivariana; Máster en Sistemas de Gestión de Calidad ISO 9001, 14001 y 18001- European Quality; Máster en Derecho Penal Internacional de la Universidad de Granada y candidata a Doctora de la misma casa de estudios; Auditora interna de European Quality.
} 
have not succeeded in eradicating it, which will only be achieved through education, awareness-raising and empowerment of potential victims. The goal of this article is to establish which is the most comprehensive denomination of the different biological stages of man, in order to obtain full protection in any national law, without taking into consideration the legal concept of person; And, secondly, to propose a current definition which, taking into account the formulas contained in relevant legal instruments, is applicable, remains in force and removes gray areas.

\section{Keywords}

Crimes, human rights, slavery, Palermo Protocol, trafficking in human beings.

\section{Introducción}

El delito de trata de seres humanos ocupa la investigación doctoral que adelanta la autora de este trabajo en la Universidad de Granada (España). Se ha escogido el tema, habida cuenta de su gran relevancia en el derecho penal internacional y en el mundo actual, dado que, al vivir en una sociedad globalizada, las fronteras se desdibujan cada vez más. En su afán por obtener las máximas ganancias posibles, el ser humano se erige como el primer y el mayor verdugo de sus congéneres; su búsqueda de utilidades o beneficios propios lo lleva a desconocer los derechos y libertades ajenos, sin importarle las consecuencias emocionales, físicas, morales o de cualquier otra índole ocasionadas a sus víctimas, quienes son concebidas como bienes objeto de negociación (Guerrero, s. f.), cosificadas y utilizadas para su propio beneficio (Fernández, 2012, pp. 99-150), lo cual evidencia una gran indiferencia frente a los padecimientos sufridos por los seres humanos en esos estados de explotación.

La comunidad internacional, consciente de la grave vulneración de los derechos humanos inherente a la trata de seres humanos, ha tejido una red de amparo basada en un principio en un tratamiento jurídico penal de esta actividad criminal y, luego, en un enfoque victimo céntrico que, por un lado, persigue la sanción ejemplar de los tratantes y el desmantelamiento de sus redes organizadas -operadas en su mayoría por organizaciones delincuenciales transnacionales- y, por el otro, procura evitar la revictimización, enfocándose en proteger y ayudar a las víctimas de este grave fenómeno criminal.

El panorama actual del delito en comento es preocupante y, junto al tráfico ilícito de migrantes -smuggling of migrants-, constituye una de las nuevas formas de esclavitud del siglo XXI reconocidas por los autores; tal denominación debería generar gran alarma, dado que son actos que niegan los logros alcanzados por la humanidad con la abolición y la prohibición de la esclavitud. La realidad que rodea la ejecución de este delito amenaza con erosionar las bases del mundo actual, al cosificar a los seres humanos y reversar los avances que la civilización alcanzó con la declaración de los derechos humanos, la generalización de la prohibición de la esclavitud humana, la prohibición del trabajo forzado, el derecho a la libertad en todas sus manifestaciones -sexual, física, laboral, profesional, de desarrollo de 
la personalidad, de tránsito, etc.-, el reconocimiento del derecho a la dignidad humana, o los derechos del ciudadano y la correlativa obligación del Estado de brindar una protección real y efectiva a sus conciudadanos, entre muchos otros, no menos importantes.

Por su parte, la ejecución de políticas estatales a gran escala que blindan al máximo las fronteras de los países y endurecen sus políticas y requisitos migratorios, perjudica el libre tránsito de las personas y el intercambio de mercancías que sí cumplen con las reglamentaciones migratorias y de comercio establecidas (Pérez, 2008, pp. 44-45); así mismo, la migración de personas entre países con fines de trabajo o residencia está viéndose afectada, a lo cual se suma la creciente e insalvable brecha económica y social (Pérez, 2008, p. 52) entre los países autoproclamados como desarrollados o primermundistas y aquellos catalogados como no desarrollados o tercermundistas. Todo lo anterior, propicia el ambiente ideal para la proliferación de los delincuentes y del crimen organizado dedicado a la trata de personas y/o el tráfico ilícito de migrantes, cuyos comportamientos no siempre se ajustan a las descripciones típicas de esos delitos e, incluso, despliegan nuevas conductas que no están contempladas en las mismas.

Este horizonte se agudiza cuando, a las implicaciones propias de la ejecución de los delitos mencionados, se suma la vulneración de los derechos de las víctimas de tales delitos y su explotación, violación, uso y abuso, lo cual genera una grave cosificación del ser humano, contraria a las evoluciones de la civilización y el derecho, en donde los delincuentes engañan o utilizan los anhelos profundos de superación de sus víctimas para someterlas a innumerables vejámenes.

La realidad actual hace ineficientes las gestiones adelantadas por la comunidad internacional para prevenir los ilícitos mencionados y solucionar las secuelas dejadas por ellos tanto en las economías de los países involucrados como en su realidad social y en las micro realidades de las víctimas y de sus familias; lo anterior, pese a los diversos instrumentos jurídicos impulsados por las organizaciones internacionales, pues los países suscriptores olvidan sus compromisos y no los convierten en una realidad para sus ciudadanos, creyendo que es suficiente transponer los postulados internacionales, sin implantar un modelo de regulación integral que sea compatible con una saludable y deseable visión victimo céntrica para que los estados puedan ocuparse, por una parte, de prevenir y penar el delito; $y$, por otra, de proteger, asistir, tratar, ayudar, reintegrar y resocializar a las víctimas de este delito. Uno de los instrumentos jurídicos internacionales más importantes en la lucha contra este evento criminal es el "Protocolo para prevenir, reprimir y sancionar la trata de personas, especialmente mujeres y niños", también denominado Protocolo de Palermo, que complementa la Convención de las Naciones Unidas contra la Delincuencia Organizada Transnacional, que este año celebrará su decimosexto cumpleaños y a pesar de este tiempo de vida, aún hay países que no lo han ratificado; o que, a pesar de haberlo suscrito o ratificado, no han cumplido de manera adecuada con las obligaciones emanadas del mismo. 
El derecho, entonces, pierde la partida al descuidar a las víctimas y limitar sus esfuerzos a contener tales conductas o sancionar las escasas veces en que son denunciadas y se consiguen las pruebas requeridas para castigarlas penalmente. Los estados parecen satisfechos, pero lo cierto es que están más preocupados por la vulneración de sus políticas migratorias que por prevenir la trata de seres humanos y, mucho menos, por brindar una ayuda integral a las víctimas de tal actividad delictiva que les permita a estas últimas superar las consecuencias de cualquier índole que perviven con ellas, les impiden el goce pleno de sus derechos y su reintegración social efectiva, y a cuyo bienestar, en tanto seres humanos, deberían propender todas las instituciones creadas por el hombre.

Con las acciones de los estados no se logra disminuir la trata de seres humanos, dado que los recursos gastados en ello no están direccionados a solucionar los efectos negativos de este ilícito ni a prevenir la captación de sus víctimas, sino que se limitan, casi siempre, a la persecución y sanción penal. Ahora bien, a pesar del gran campo de estudio que abarca el delito de trata de seres humanos, este artículo se ocupa de analizar dos grandes tópicos: de un lado, indaga cuál acepción -'trata de personas' o 'trata de seres humanos'- incluye mejor los diferentes estadios de la vida humana $y$, por ende, las lesiones que ocasionan estos comportamientos; $y$, del otro, se pregunta cuál sería la definición más acertada, especializada y comprensiva del mayor número de situaciones constitutivas de trata -en la actualidad o en el futuro-. Ninguno de los dos temas resulta sencillo y, de hecho, cada uno daría, por sí solo, para múltiples discusiones e investigaciones, pero la idea de unirlos en esta reflexión tiene la finalidad de sensibilizar a los estados y a las instituciones para que se preocupan por mitigar los efectos de este flagelo, así como a cualquier persona interesada en el tema, de tal manera que se facilite el entendimiento del delito y el conocimiento de sus características.

\section{¿Trata de personas o trata de seres humanos?}

Para adentrarse en las disquisiciones sobre el delito de trata, es conveniente compartir algunas conclusiones a las que se ha arribado en el desarrollo de la tesis doctoral que sirve de marco a esta reflexión, de cara a establecer cuál sería la denominación más adecuada para este delito -'trata de personas' o 'trata de seres humanos'-, en la medida en que permita proteger la mayor cantidad de etapas de la vida humana. No sin antes advertir que las mismas podrán variar a partir de la definición legal que cada ordenamiento jurídico establezca para los términos 'persona' y 'ser humano'.

Tal y como enseña la tradición clásica, sintetizada por el diccionario de la Academia de la Lengua española (s. f.), la palabra persona, etimológicamente, proviene del latín persōna que significaba máscara de actor, personaje teatral, personalidad, persona $y$, aunque otros autores indican que su origen es la palabra latina per-sonare, que significaba sonar a través de, lo cierto es que todos coinciden en que tales expresiones latinas provienen del etrusco фersu (phersu) que, a su vez, proviene del

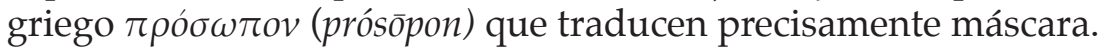


Así, la palabra persona, en consonancia con lo señalado por diversos autores (Cruz, 2011; Vela, 2005; Betancur, 2010, pp. 127-143; Alva, 2008), se refiere a la máscara que se ponían los actores griegos y romanos en sus representaciones teatrales, que contaba con un mecanismo de abocinamiento vocal o una especie de bocina que permitía darle mayor resonancia o proyección a la voz del actor, de modo que llegara a todos los espectadores y que, además, permitía cambiar sus facciones para aproximarlas a la esencia del personaje representado. Según De Aránzazu (2007, pp. 269-279), debido a una serie de trasposiciones, la palabra persona se aplicó al actor primero y, luego, a los actores de la vida social y jurídica, considerados como sujetos de derechos y obligaciones.

Por esto, al profundizar en su significado filosófico, se precisa que ser persona es representar un rol ante el mundo, en la sociedad, es tener voz. La máscara oculta el rostro, pero detrás está el verdadero individuo de la especie humana, el ser humano, a quien en el ámbito jurídico se le llamó ‘sujeto de derechos'. Con el tiempo, la palabra persona ha pasado a ser utilizada para denominar a todos los individuos de la especie humana, al punto de entenderse que la persona está detrás de la personalidad, de la máscara o del aspecto que el hombre muestra y usa ante la sociedad para hacerse oír, esto es, utilizar sus derechos.

Dejando de lado las bases etimológicas y el uso común de la palabra persona, importa detenerse ahora en su uso en el discurso jurídico legal, esto es, en su concepto jurídico. En este contexto, persona es aquel ser con aptitud o voluntad para ser sujeto de derechos y obligaciones, asimilándose a la personalidad; para ello, se deben reunir unas ciertas condiciones impuestas por el legislador, las cuales varían en cada país y que se pueden sintetizar en que el ser humano nazca y perviva a su separación del vientre materno, como requisitos básicos, pero no únicos en algunos derechos.

Por su parte, el de ser humano es un concepto biológico (Acfilosofia, s. f.) que comprende a todos los miembros de la especie humana desde su concepción, aunque no todos lleguen a ser reconocidos como persona para el derecho. Según los últimos avances científicos, los seres humanos comparten la misma naturaleza conforme lo indica el análisis reciente del genoma humano, el cual es idéntico en los seres humanos en un 99,9 \% (Consejo Argentino para la Información y el Desarrollo de la Biotecnología, s. f.; Ramírez, 2005), el 0,1 \% restante es la pequeña diferencia, divergencia o polimorfismo genético que distingue un ser humano de otro, en aspectos como el sexo, el color de la piel, de ojos o de cabello, la altura, el peso, la fisionomía, etc., pero sin desligarlo de su especie. De lo cual se puede deducir que todos los seres humanos comparten una misma naturaleza y, por ello, deben gozar, en principio, de los mismos derechos y protecciones, sin importar si han cumplido los requisitos legales para ser considerados personas.

A tono con el Código Civil español vigente, la disposición final tercera de la Ley 20 de 2011 dispone que "[1]a personalidad se adquiere en el momento del nacimiento con vida, una vez producido el entero desprendimiento del seno 
materno" (art. 30), por lo cual es persona el concebido luego de su nacimiento con vida tras la separación total de su madre. La misma codificación establece que "[e] 1 nacimiento determina la personalidad; pero el concebido se tiene por nacido para todos los efectos que le sean favorables, siempre que nazca con las condiciones que expresa el artículo siguiente" (art. 29), con lo cual se estatuye la favorabilidad frente a los derechos que, si bien, al no ser aún considerado persona, esto es, sujeto de derechos, no puede ejercer a plenitud, sí podrá hacerlo su representante legal cuando sean favorables al concebido y a condición de que nazca vivo y se separe por completo de su madre (art. 30).

Según Cabanillas (1993), hasta antes de la reforma mencionada, la codificación española establecía que "[p]ara los efectos civiles, sólo se reputará nacido el feto que tuviere figura humana y viviere veinticuatro horas enteramente desprendido del seno materno", lo cual generó múltiples y dispares discusiones, que no pueden reproducirse ahora. La reforma de 2011 armonizó la reglamentación española con los conceptos hoy aceptados, dejando de lado los problemas asociados a las 24 horas de pervivencia requeridas y poseer 'figura humana', requisitos arcaicos (Macanás, 2013), nacidos en un derecho oscurantista plagado de creencias fantásticas y discriminadoras, que generaba muchas y disímiles dificultades en la praxis jurídica.

El Código Civil colombiano vigente señala: “Personas Naturales. Son personas todos los individuos de la especie humana, cualquiera que sea su edad, sexo, estirpe o condición" (art. 74). Lo cual se complementa con las previsiones del art. 90 ibidem:

[1]a existencia legal de toda persona principia al nacer, esto es, al separarse completamente de su madre. La criatura que muere en el vientre materno, o que perece antes de estar completamente separada de su madre, o que no haya sobrevivido a la separación un momento siquiera, se reputará no haber existido jamás.

Al igual que en el derecho español, el ordenamiento civil colombiano brinda protección al ser humano concebido que está por nacer (art. 91):

[1]a ley protege la vida del que está por nacer. El juez, en consecuencia, tomará, a petición de cualquiera persona, o de oficio, las providencias que le parezcan convenientes para proteger la existencia del no nacido, siempre que crea que de algún modo peligra.

De igual forma, en el art. 93 ejusdem el citado legislador señala los derechos diferidos del que está por nacer, así:

[1]os derechos que se diferirían a la criatura que está en el vientre materno, si hubiese nacido y viviese, estarán suspensos hasta que el nacimiento se efectúe. Y si el nacimiento constituye un principio de existencia, entrará el recién nacido en el goce de dichos derechos, como si hubiese existido al tiempo en que se defirieron. En el caso del inciso del artículo 90 pasarán estos derechos a otras personas, como si la criatura no hubiese jamás existido. 
En el derecho peruano, por su parte, según el Código Civil vigente, "[1]a persona humana es sujeto de derecho desde su nacimiento. La vida humana comienza con la concepción. El concebido es sujeto de derecho para todo cuanto le favorece. La atribución de derechos patrimoniales está condicionada a que nazca vivo" (art. 1).

El sujeto de derecho es, entonces, en Perú, el ser humano desde su concepción hasta su muerte, considerado individual (persona natural o física o concebido) o colectivamente (persona jurídica $u$ organizaciones de personas no inscritas). Lo cual es recogido en Fernández (s. f.) cuando precisa:

[s]ólo el ser humano, en cualquiera de sus cuatro "maneras de ser", es sujeto de derecho. Es decir, individual o colectivamente considerado. Ningún otro ente de la naturaleza es sujeto de derecho. De lo expuesto se desprende, por consiguiente, que sólo lo que jurídicamente se alude como "persona" es sujeto de derecho. Es decir, la persona es sujeto de derecho en cuanto ser humano, en cualquiera de las mencionadas cuatro maneras de presentarse en el mundo. Aunque a nivel de la doctrina -al menos en la peruana-, por el momento, el término persona se reserva sólo para el ser humano nacido - persona natural-y para el ser humano que constituye una "organización de personas" inscrita y que, por este hecho, como está dicho, adquiere un estatuto legal de excepción. El concebido, sin embargo, es una persona por nacer, tal como se le reconoce en la doctrina y en la legislación argentina. Sólo no se menciona como persona a la "organización de personas no inscrita", desde que el adjetivo de 'jurídica' lo expropiaron los pandectistas para designar a la organización de personas 'inscrita'.

Por supuesto, cuando en la transcripción se habla de cuatro maneras de ser se hace referencia a que en ese país se reconocen esas clases de sujeto de derecho: El concebido (persona por nacer o nasciturus), la persona natural, la persona jurídica y las organizaciones de personas no inscritas (asociación, fundación y comités no inscritos). Ahora bien, en relación con el concebido como sujeto de derecho rige la condición suspensiva de la efectividad de sus derechos patrimoniales, lo que, en palabras del Tribunal Supremo

no significa que aquellos derechos no existan para el concebido, sino que antes de que se produzca el hecho del nacimiento con vida, aquel concebido no tiene capacidad para recibir, verbi gratia, donaciones, legados o indemnizaciones; pero una vez nacido tiene derecho a recibirlos (Corte Suprema de Justicia del Perú, sentencia 1486-2007 de 2008).

Con base en las acepciones ya señaladas y originadas en los tres derechos aludidos y de las conceptualizaciones filosóficas sobre el tema, se puede observar que desde las perspectivas doctrinaria y legal se ha aceptado el término ser humano como comprensivo de todos los instantes de la vida humana, que incluye a individuos de la especie natural humana; mientras que, la voz persona, vista desde la óptica jurídica y no sociológica o cultural, se circunscribe al cumplimiento de unos requisitos legales que demuestren no solo la vida sino la perdurabilidad de la mis$\mathrm{ma}$, todo para fines y discusiones legales, por lo general en lo relativo a derechos de patrimoniales o sucesorales. 
Por ello, para ser reconocido como persona en Colombia y España se exige que el ser humano no nacido o concebido o nasciturus nazca vivo y se separe, por completo, de la madre; mientras que, en Perú, solo se requiere que nazca vivo, sin mencionar la separación completa de la madre (lo cual puede generar algunos debates legales). Esta declaración es apoyada por la codificación peruana cuando establece que todo individuo desde su concepción es ser humano; El art. 1 del Código Civil peruano señala: "[1] a vida humana comienza con la concepción". En Colombia se emplean las expresiones 'criatura' o 'el que está por nacer', sin más precisiones y, en España, se usa la denominación 'concebido'.

En consecuencia, y para los propósitos de este trabajo, se asume la acepción de trata de seres humanos, por ser comprensiva de un mayor número de realidades, lo cual permite incluir en dicho crimen aquellos eventos delictivos acaecidos sobre seres humanos no nacidos o concebidos no nacidos, o que aún no han cumplido con los requisitos legales de la personalidad, dado que estos seres humanos para la mayoría de los derechos no son personas desde el punto de vista jurídico, en el sentido de que no gozan de la plenitud de los derechos inherentes a la personalidad, aunque gocen de algunas protecciones legales.

Si, por el contrario, se tomara el término persona, quedarían por fuera del delito estudiado múltiples realidades, especialmente lesivas de la dignidad del ser humano y de sus derechos humanos inalienables, como cuando se ejerce la trata sobre una mujer embarazada, o se le despoja de su hijo nacido o se le practica un aborto; o si, obsérvese, una mujer embarazada víctima de trata, por las lesiones sufridas, pierde a su hijo no nato, o cuando se somete a una mujer bajo los padecimientos de este delito, con el fin de obligarla a la procreación de niños, etc.

Otros casos que podrían quedar por fuera del tipo penal de trata, si se la concibe referida solo a personas, se podrían presentar en sistemas jurídicos donde aún se mantengan condiciones arcaicas, como las establecidas en el antiguo derecho civil español, cuando se era persona solo luego de pervivir 24 horas posteriores al alumbramiento, de tal forma que si un ser humano era víctima de trata en este interregno, en tal derecho hipotético se encontraría desprovista de protección efectiva del Estado y, peor aún, sus victimarios realizarían una acción atípica por lo cual no podrían ser perseguidos o sancionados.

Por lo expuesto, aquí se promueve la titulación universal del delito como 'trata de seres humanos', con el fin de comprender todos los eventos en que se involucre la explotación de seres humanos, sin importar la definición de persona que tenga el derecho interno de cada país, para incluir situaciones ubicadas en fronteras grises indefinidas y en las cuales, a pesar de que el derecho no reconozca al ser humano personalidad jurídica, es innegable su condición de tal y, por ende, existe la obligación de conceder la protección que brinda la tipificación penal.

Además, con tal denominación se evitan en esos sistemas jurídicos discusiones sobre si la víctima era persona o no, dado que el fin de la reglamentación mundial contra la trata de personas es proteger a todos los seres humanos sumidos en tan 
degradantes situaciones de explotación, atentatorias contra la dignidad y de los derechos humanos, sin importar si está concebido y no nacido o ha nacido, pero sin cumplir aún con los requisitos legales para adquirir la personalidad, primando, entonces, el hecho innegable de nacer con vida.

De todo lo expuesto, se puede deducir que es más omnicomprensiva la locución de trata de seres humanos, porque abarca todos los estadios del ser humano como ser biológico, esto es, desde la concepción hasta la muerte. A su turno, el término persona ha sido acuñado desde la perspectiva jurídica para referirse, en principio, a la adquisición y a la posibilidad de disponer de los derechos derivados de la personalidad, vale decir, igual a la capacidad de relacionarse desde el punto de vista del derecho, para lo cual cada ordenamiento concreto exige el cumplimiento de uno o varios requisitos que pueden variar (haber nacido con vida y separarse por completo del vientre materno; haber nacido con vida; o, en fin, cualquier otra exigencia como el tiempo de pervivencia adicional al nacimiento).

Lo anterior, sin desconocer que en algunas legislaciones se nombra a este delito como trata de personas, debido a su traducción literal del inglés trafficking in persons, nombre establecido por el "Protocolo para prevenir, reprimir y sancionar la trata de personas, especialmente mujeres y niños, que complementa la Convención de las Naciones Unidas contra la delincuencia organizada transnacional", también conocido como Protocolo de Palermo y, en tales eventos, ese será el nombre a usar en este estudio, para hacer una referencia adecuada a tales sistemas. El origen de esta discusión ocurre durante el proceso de elaboración de los Protocolos que complementan la Convención de las Naciones Unidas contra la Delincuencia Organizada Transnacional mencionada, momento en el cual varias delegaciones señalaron los problemas que planteaba la traducción de los términos Trafficking in Persons y Smuggling of Migrants del inglés a otros idiomas, cuyos significados en español son, respectivamente, tráfico de personas y contrabando de migrantes.

\section{La noción en los instrumentos jurídicos internacionales y algunas definiciones complementarias}

Para arribar a una concepción del delito de trata de seres humanos es indispensable principiar por el estudio de las definiciones legales contenidas en los instrumentos jurídicos internacionales, regionales (europeos y americanos) y nacionales (de los países de España, Colombia y Perú) pertinentes. Esto, debido a que la trata de seres humanos es, sin duda, uno de los delitos que plantea una verdadera problemática no solo desde el punto de vista dogmático, sino desde la óptica de la política criminal, al ser un crimen atroz que afecta la dignidad humana en todas sus esferas, pues se comercializa con seres humanos como si fueran bienes de libre circulación en el mercado, lo cual constituye una forma extrema de explotación y de violación de los derechos humanos.

Con el fin de hacer frente a este fenómeno, que por infortunio aumenta en proporciones alarmantes, hasta considerarse una de las conductas delictivas de mayor provecho económico en la actualidad y que impacta de manera directa a un nú- 
mero indeterminado de personas con funestas consecuencias, los ordenamientos jurídicos nacionales, regionales e internacionales, han diseñado un marco normativo en virtud del cual se busca que los estados compaginen sus esfuerzos y adopten medidas normativas y políticas públicas coherentes, aplicables desde el punto de vista social y jurídico, como mecanismos válidos de control formal y de lucha contra el delito de trata de seres humanos. A este respecto, téngase en cuenta que según los datos publicados en el documental 'Trata de mujeres: de Tenancingo a Nueva York' (Discovery, 2016), el delito de trata de personas, pasó de ocupar el tercer puesto en el ámbito mundial, después de la venta ilegal de armas y el tráfico de drogas ilícitas, al segundo, lo cual evidencia la gran cantidad de dinero que mueven estas organizaciones delincuenciales; la CNN generó también un documental sobre este tema en el 2015 y otros documentales sobre trata de seres humanos están disponibles en internet, en el portal YouTube.

De esta manera, aunque los estados no den cumplimiento adecuado a los compromisos adquiridos, es un gran avance que los organismos internacionales, regionales y nacionales, se ocupen del tema, pues ello constituye un punto de partida necesario para sensibilizar sobre tal realidad. Al estudiar el iter criminis del delito de trata de seres humanos y con base en las posiciones doctrinarias mayoritarias, se puede establecer una clasificación de los tipos o dimensiones de la trata de seres humanos según el lugar de traslado y/o explotación final de la víctima, así:

De un lado, la trata interna o doméstica. La víctima es explotada en su zona de origen o es trasladada para su explotación dentro de las fronteras de un mismo país, por lo general es el de origen que no se refiere al sitio de nacimiento de la víctima, sino al lugar donde se inicia todo el proceso de captación o enganche, siendo en algunos casos coincidentes, pero no así en todos.

Del otro, la trata internacional o externa. Ocurre cuando para su explotación la víctima es trasladada fuera de las fronteras de su país de origen, bien dentro de la misma región geográfica, o, bien, fuera de ella; este tipo de trata se caracteriza porque la captación o enganche ocurre en el país de origen de la víctima y la explotación acaece en uno diferente, con lo cual se requiere el cruce de fronteras de la nación de la víctima hasta el sitio final de su explotación. Dentro de este tipo de trata se distinguen dos subtipos o subdimensiones, ayudados de la división establecida por la Organización de Naciones Unidas - ONU (2009) de 11 regiones del mundo: la trata intrarregional, que se presenta cuando para su explotación la víctima es trasladada fuera de las fronteras de su país de origen, pero dentro de una misma región geográfica, usualmente se da el cruce de fronteras entre países cercanos desde el punto de vista geográfico; y la trata interregional, cuando para su explotación la víctima es trasladada fuera de las fronteras de su país de origen traspasando una o varias regiones geográficas, que no necesariamente son cercanas.

$\mathrm{Al}$ respecto, adviértase que en las conclusiones contenidas en el Informe citado, las Naciones Unidas identifican tres dimensiones o tipos de trata de seres humanos, según sus flujos, tal y como se indica a continuación, las cuales se emplean en 
los subsecuentes informes anuales que ese organismo redacta sobre esta actividad criminal: trata interregional, trata intrarregional y trata doméstica o interna. En tal documento, en las páginas 16 y 17, la ONU divide al mundo en 11 regiones a saber: Medio oriente y Norte de África, África occidental y central, África del este, África del sur, Norteamérica, América central y Caribe, América del sur, Asia del este y pacífico, Asia del sur y Sudoeste asiático, Europa del este y Asia central y Europa occidental y central.

\section{Análisis de las definiciones legales del delito de trata de seres humanos.}

Son varios los instrumentos jurídicos internacionales, regionales y nacionales, que contienen alguna definición o tratan el delito en estudio, pero ha sido la presión de los organismos internacionales la razón por la cual los gobiernos nacionales definen y tratan a nivel estatal este tipo de actividad criminal. Por eso, sin temor a equívocos, se puede decir que los instrumentos jurídicos internacionales y regionales han sido los precursores de las tipificaciones nacionales y de las definiciones usadas o acuñadas por la doctrina.

Así las cosas, se debe iniciar por el estudio de las definiciones legales del delito de trata de seres humanos relevantes para los países analizados; por ello, una vez examinadas todas ellas y las normas in extenso, puede decirse que la noción rectora en el ámbito mundial es, con algunas variaciones, la establecida en el art. 3 del "Protocolo para prevenir, reprimir y sancionar la trata de personas, especialmente mujeres y niños, que complementa la Convención de las Naciones Unidas contra la delincuencia organizada transnacional", también conocido como Protocolo de Palermo, expedido en Italia en el año 2000, en el marco de la Conferencia Mundial convocada por la ONU, que entró en vigor el 25 de diciembre de 2003. En relación con ello, se debe tener en cuenta que los instrumentos jurídicos estudiados son: el "Protocolo para prevenir, reprimir y sancionar la trata de personas, especialmente mujeres y niños, que complementa la "Convención de las Naciones Unidas contra la delincuencia organizada transnacional" (artículo 3.2.); la Directiva 2011/36/UE del Parlamento Europeo y del Consejo de 5 abril de 2011, "relativa a la prevención y lucha contra la trata de seres humanos y a la protección de las víctimas y por la que se sustituye la Decisión marco 2002/629/JAI del Consejo" (Artículos 2, 3 y 5. 3); la "Comunicación de la Comisión al Parlamento Europeo, al Consejo, al Comité Económico y Social Europeo y al Comité de las Regiones-Estrategia de la UE para la erradicación de la trata de seres humanos (2012-2016)/COM/2012/0286 final" (apartado 1); el "Convenio 197 del Consejo de Europa sobre la lucha contra la trata de seres humanos", (Artículo 4. 5.); la "Convención Interamericana sobre tráfico internacional de menores" (Artículo 2. 6); la "Declaración interamericana para enfrentar la trata de personas, nombrada también como Declaración de Brasilia, aprobada en la $3^{\text {a }}$ Sesión Plenaria del Consejo Permanente de la Organización de Estados Americanos-Comisión de Seguridad Hemisférica", celebrada el 5 de Diciembre de 2014, en el marco de la cuarta reunión de autoridades nacionales en materia de trata de personas; el "II Plan de trabajo para combatir la trata de personas en el hemisferio occidental -2015-2018-"; y la "Convención interamericana 
para prevenir, sancionar y erradicar la violencia contra la mujer o Convención de Belém do Pará. Belém Do Pará" (1994).

De la legislación española: Ley Orgánica 4 de 2000 sobre "derechos y libertades de los extranjeros en España y su integración social", modificada por las siguientes leyes: Ley Orgánica 5 de 2010 "por la que se modifica la Ley Orgánica 10/1995"; Ley Orgánica 11 de 2003 "de medidas concretas en materia de seguridad ciudadana, violencia doméstica e integración social de los extranjeros"; Ley Orgánica 13 de 2007 "para la persecución extraterritorial del tráfico ilegal o la inmigración clandestina de personas"; Ley Orgánica 1 de 2015 "por la que se modifica la Ley Orgánica 10 de 1995".

De la legislación peruana: Código Penal peruano (1991); Constitución Política peruana (1993); Ley 26309 "por la cual se adiciona el artículo 153 A" a la Codificación Penal peruana, erigiendo la forma agravada del delito de trata de personas, modificada por la Ley 28950 de 2007; Ley 28950 de 2007 "Por la cual se modifican dispositivos del Código Penal en materia de trata de personas y el tráfico Ilícito de migrantes"; Decreto Supremo 007-2008 de 2008 "por el cual se aprueba el Reglamento de la Ley 28950 - Ley contra la Trata de Personas y Tráfico Ilícito de Migrantes".

De Colombia: Decreto 100 de 1980 "por el cual se expide el Código Penal"; Constitución Política (1991); Ley 599 de 2000 "por la cual se expide el Código Penal"; Ley 985 de 2005 "por medio de la cual se adoptan medidas contra la trata de personas y normas para la atención y protección de las víctimas de la misma"; Ley 1453 de 2011 "por medio de la cual se reforma el Código Penal, el Código de Procedimiento Penal, el Código de Infancia y Adolescencia, las reglas sobre extinción de dominio y se dictan otras disposiciones en materia de seguridad". De igual manera, se ha hecho una revisión y un estudio exhaustivo de la bibliografía disponible en formato físico y/o digital sobre el tema y de ella se han extraído las posiciones y los tratamientos doctrinarios más relevantes, pero por cuestiones de espacio, no es posible enunciarlos en este artículo.

En relación con el artículo $3^{\circ}$ arriba citado, se puede decir que él es el primer instrumento internacional en definir la trata con las características actuales de tal actividad criminal y en instar a los Estados a crear mecanismos para su prevención, legislar internamente para combatirla y capacitar a sus funcionarios para aplicar dicha legislación; obsérvese:

\section{Artículo 3 - Definiciones}

Para los fines del presente Protocolo:

a) Por "trata de personas" se entenderá la captación, el transporte, el traslado, la acogida o la recepción de personas, recurriendo a la amenaza o al uso de la fuerza u otras formas de coacción, al rapto, al fraude, al engaño, al abuso de poder o de una situación de vulnerabilidad o a la concesión o recepción de pagos o beneficios para 
obtener el consentimiento de una persona que tenga autoridad sobre otra, con fines de explotación. Esa explotación incluirá, como mínimo, la explotación de la prostitución ajena u otras formas de explotación sexual, los trabajos o servicios forzados, la esclavitud o las prácticas análogas a la esclavitud, la servidumbre o la extracción de órganos;

b) El consentimiento dado por la víctima de la trata de personas a toda forma de explotación que se tenga la intención de realizar descrita en el apartado a) del presente artículo no se tendrá en cuenta cuando se haya recurrido a cualquiera de los medios enunciados en dicho apartado;

c) La captación, el transporte, el traslado, la acogida o la recepción de un niño con fines de explotación se considerará "trata de personas" incluso cuando no se recurra a ninguno de los medios enunciados en el apartado a) del presente artículo;

d) Por "niño" se entenderá toda persona menor de 18 años.

De la noción sub examine se extraen tres elementos esenciales del delito de trata de personas que están vinculados o interrelacionados de forma estrecha: la actividad (o el enganche); los medios (o la forma en que se engancha); y el propósito o fin (la explotación). Fundado en ellos, la trata de personas que pretende proscribir el Protocolo de Palermo se puede sintetizar como una actividad que, al utilizar determinados medios, tiene como propósito o fin la explotación. Estos elementos se van a desarrollar a continuación con base en la cartilla elaborada por la Comisión Interamericana de Mujeres -CIM- de la Organización de Estados Americanos -OEA-, la Organización Internacional para las Migraciones -OIM-, y el Instituto Nacional de Migración y el Instituto Nacional de las Mujeres de México, por su vigencia, simplicidad y didáctica (2006).

\section{La actividad.}

Para el Protocolo, este elemento se resume en "la captación, transporte, traslado, acogida o recepción de personas" deduciéndose, entonces, con base en los análisis efectuados por los doctrinantes y estudiosos, que la misma se desarrolla en tres momentos diferenciados: captación o enganche; transporte y traslado; y recepción y acogida.

En la captación o enganche, se pretende ganar la voluntad, atraer o reclutar a quien va a ser víctima de este delito, lo cual se realiza -de forma usual- en el lugar de origen de la víctima, mediante ofertas laborales atractivas, posibilidades de migración con la expectativa del mejoramiento de su vida o la posibilidad de ayudar a sus familiares, facilidades económicas y/o un sin número de promesas que se aprovechan de los deseos de las personas y de sus esperanzas de superación.

Muchos expertos coinciden en que, en la mayoría de los casos, el captador o reclutador pertenece al mismo entorno social de la víctima, lo que genera en ella la confianza necesaria para aceptar la oferta y que, en los casos de seres humanos concebidos, pero aún no nacidos, menores de edad o mujeres, puede encontrarse 
otro delito de por medio, como es su venta por parte de los adultos responsables de su guarda, cuidado y protección.

El transporte y traslado implican el desplazamiento físico de las víctimas, impulsado por los tratantes desde el lugar de origen o captación al lugar de destino, con fines de explotación. Se cumple con este segundo momento al generar las condiciones para garantizar lo uno o lo otro, sea orientándolo, facilitándolo, acompañándolo o realizándolo; puede incluir desde el pago de pasajes, la compra directa de pasajes por parte de los tratantes, el traslado en vehículos propios o de terceros, la facilitación del contacto con terceros para el traslado, la instrucción de las víctimas para su desplazamiento y llegada a destino, etc. Cabe señalar que, por lo general, las víctimas viajan acompañadas por un miembro de la organización, quien se asegura de que lleguen a destino, pero, cuando ellas viajan engañadas por un falso aviso de empleo, suelen desplazarse solas, incluso por sus propios medios.

En los casos en los cuales se cruzan fronteras, las víctimas suelen hacer uso de su propia documentación (la misma que luego se les sustrae o decomisa por los tratantes una vez han arribado al destino de la explotación o luego de realizados los pasos requeridos por los controles migratorios), sin desconocer los casos en donde se emplea documentación falsa o irregular. Al tratarse de menores de edad, los tratantes prefieren hacerlos cruzar la frontera con documentación falsa, para no delatar la minoría de edad o, en numerosos eventos, viajan con autorización de sus propios padres o representantes legales, quienes, a sabiendas o no del aberrante fin de explotación que les espera, los entregan a los tratantes a cambio de diversos beneficios; aunque los tratantes también son hábiles a la hora de engañar a los padres o tutores para conseguir tal autorización, asegurándoles mejores condiciones de vida para sus hijos o prohijados.

En un gran número de situaciones, la víctima coopera con el tratante frente a las autoridades, pues, en general, no sabe que con posterioridad será explotada; en esta fase, los enemigos de las víctimas son las autoridades de control migratorio fronterizo de cada país que las separan del país de destino deseado.

Para concluir, la recepción y acogida implican recibir o albergar a la víctima en cualquier etapa del proceso, con el propósito de asegurar su disponibilidad tal y como si fuere una mercancía. No importa que la recepción o acogida se haga con el consentimiento de la víctima ni que se realice en unas buenas condiciones. Sin embargo, el estudio de casos muestra que en este momento de la actividad los tratantes destapan sus verdaderas intenciones; las víctimas son golpeadas por su trágica realidad y son sometidas a alojamientos con pésimas condiciones físico-sanitarias y empiezan los vejámenes y las diversas formas de explotación que les tienen preparadas.

Luego de este primer contacto con la realidad de la explotación, las víctimas son mantenidas bajo un estricto control por sus tratantes o por su explotadores finales; para ello, se utilizan diversas técnicas de fuerza, coacción, coerción, abuso de la posición dominante frente a la víctima o de una situación de vulnerabilidad de la 
víctima, como, por ejemplo, la privación o restricción de la libertad, el control del contacto con familiares y otras personas, los malos tratos físicos y psicológicos, la retención de la documentación, el suministro de drogas y alcohol, las amenazas para la integridad física o moral de la víctima o de sus familiares o amigos, las amenazas con contarle a sus parientes o amigos las actividades que han sido obligadas a realizar, entre muchas otras formas.

\section{Los medios.}

Este segundo elemento da cuenta de las diversas formas utilizadas para realizar la trata de personas. La definición en estudio las describe así: "la amenaza o uso de la fuerza, coacción, rapto, fraude, engaño, abuso de poder, vulnerabilidad, la concesión o recepción de pagos o beneficios para obtener el consentimiento de una persona que tenga autoridad sobre otra con fines de explotación". Se trata de una lista taxativa de medios, lo cual es un grave desacierto porque debió propender por un listado ejemplificativo de los usados por los tratantes, sin desconocer los medios nuevos o no descubiertos empleados o que podrían usar los tratantes para obtener la explotación de sus víctimas.

Sin embargo, no hay que desconocer que esta definición es bastante completa y comprensiva de múltiples realidades, aunque bien podría ser perfeccionada en el sentido antes mencionado, lo cual se soluciona con facilidad mediante la inclusión de fórmulas como 'entre otros medios', 'o cualquier otro medio' u otra que permita entender, sin temor a equívocos, que la tipificación incluye cualquier otro medio por el cual el tratante garantice su fin de explotación.

Por otra parte, el Protocolo establece que cuando las víctimas sean niños, esto es, menores de 18 años, no se necesita que existan los medios antes estudiados para que la actividad se califique como trata de seres humanos, al precisar en el inciso c del artículo en estudio que "[1]a captación, el transporte, el traslado, la acogida o la recepción de un niño con fines de explotación se considerará 'trata de personas' incluso cuando no se recurra a ninguno de los medios enunciados en el apartado a) del presente artículo".

\section{El propósito o fin: la explotación.}

El Protocolo lo concibe en su acepción amplia, que permite incluir cualquier tipo de explotación tal y como establece la definición: "[e]sa explotación incluirá, como mínimo, la explotación de la prostitución ajena u otras formas de explotación sexual, los trabajos o servicios forzados, la esclavitud o las prácticas análogas a la esclavitud, la servidumbre o la extracción de órganos". Esto significa un gran avance, dado que al no crearse un tipo cerrado frente a las finalidades perseguidas pueden incorporarse finalidades no conocidas en la actualidad por los tratantes y que podrían surgir en el futuro. Ahora bien, la definición del Protocolo de Palermo hace referencia expresa al consentimiento dado por la víctima de trata y precisa que el mismo se tendrá por inexistente, esto es, no se tendrá en cuenta cuando se haya recurrido a cualquiera de los medios enunciados en la definición estudiada. 
Por último, debe indicarse que, de acuerdo con la definición sub examine, para que se configure el delito estudiado, los componentes o elementos indicados deben considerarse de manera conjunta, es necesario que estén conectados, por lo cual, aunque no se haya consumado el delito por estar aún en alguna de las fases previas del iter criminis, si se logra establecer la relación mencionada se estará frente a un caso de trata.

A continuación, se aborda un instrumento jurídico regional europeo aplicable a uno de los países sobre los cuales versa este estudio -España-, cual es, la Directiva 2011/36/UE del Parlamento Europeo y del Consejo (2011), relativa a la "Prevención y Lucha Contra la Trata de Seres Humanos y a la Protección de las Víctimas y por la que se sustituye la Decisión marco 2002/629/JAI del Consejo". Esta directiva establece las normas mínimas relativas a la definición de las infracciones penales y de las sanciones en el ámbito de la trata de seres humanos a nivel europeo e introduce disposiciones comunes teniendo en cuenta la perspectiva de género para mejorar la prevención de este delito y la protección de las víctimas; dice así:

\section{Artículo 2. Infracciones relacionadas con la trata de seres humanos:}

1. Los Estados miembros adoptarán las medidas necesarias para garantizar que sean punibles las conductas siguientes cuando se cometan intencionadamente:

La captación, el transporte, el traslado, la acogida o la recepción de personas, incluido el intercambio o la transferencia de control sobre estas personas, mediante la amenaza o el uso de la fuerza u otras formas de coacción, el rapto, el fraude, el engaño, el abuso de poder o de una situación de vulnerabilidad, o mediante la entrega o recepción de pagos o beneficios para lograr el consentimiento de una persona que posea el control sobre otra persona, con el fin de explotarla.

2. Existe una situación de vulnerabilidad cuando la persona en cuestión no tiene otra alternativa real o aceptable excepto someterse al abuso.

3. La explotación incluirá, como mínimo, la explotación de la prostitución ajena, u otras formas de explotación sexual, el trabajo o los servicios forzados, incluida la mendicidad, la esclavitud o prácticas similares a la esclavitud, la servidumbre, la explotación para realizar actividades delictivas o la extracción de órganos.

4. El consentimiento de una víctima de la trata de seres humanos para su explotación, prevista o consumada, no se tendrá en cuenta cuando se haya recurrido a cualquiera de los medios contemplados en el apartado 1.

5. Cuando la conducta a que se hace referencia en el apartado 1 afecte a un niño, constituirá infracción punible de trata de seres humanos aun cuando no se haya recurrido a ninguno de los medios contemplados en el apartado 1 .

6. A efectos de la presente Directiva, se entenderá por «menor» cualquier persona menor de dieciocho años. 
Lo primero a resaltar es que el delito de trata descrito requiere demostrar la intencionalidad en la ejecución de las acciones para su tipicidad, lo que en derecho penal equivale al dolo dejando por fuera las conductas en las cuales no se demuestre esa intencionalidad dañosa, es decir, las culposas. También, se observa que la descripción de la conducta típica abarca todos los verbos rectores contenidos en la definición del Protocolo de Palermo, pero incluye el intercambio y la transferencia de control sobre las víctimas, para tipificar dos situaciones ubicadas en la frontera gris de la definición, porque dentro de la ejecución del delito mencionado puede ocurrir que el primer tratante intercambie a su víctima con un segundo tratante o con un tercero o transfiera el control que posee sobre la víctima a otro tratante o a un tercero. Con esta adición, se logra, entonces, sancionar ambos tratantes o al primer tratante y al tercero.

Así mismo, la directiva en revisión adiciona otro elemento que debe entenderse como explotación: el aprovechamiento para realizar actividades delictivas. El comentado se entiende comprendido en la definición del Protocolo de Palermo tácitamente, pero, al incluirlo de forma expresa, se amplía el ámbito típico del delito para incluir una explotación en la cual se obligue a la víctima a cometer cualquier delito; este supuesto se incluyó debido a las fronteras grises surgidas al enfrentar la definición del Protocolo de Palermo con la realidad de la ejecución del delito de trata de seres humanos. En todo caso, es preferible dejar enunciadas las formas de comisión conocidas y utilizar una fórmula abierta para incluir las futuras o actualmente desconocidas, con eso se hace una mayor claridad en la aplicación del tipo.

Otra situación que constituye un gran avance en la definición del delito de trata de seres humanos es lo previsto en el art. $5^{\circ}$ de la Directiva, relativo a la responsabilidad de las personas jurídicas. De este modo, se evita que los seres humanos que actúan y deciden por la persona jurídica infractora se escuden en la irresponsabilidad de esta última y eludan responsabilidades y mantengan activos negocios que muestran una fachada de legalidad, como por ejemplo, agencias de modelos, agencias de colocación de empleos o empresas que ofrecen aprender otro idioma de forma rápida mediante la inserción total en un país que hable tal idioma, bien sea indicando que deben realizar algún tipo de trabajo para pagar su estadía o sin informar tal situación, pero que, en su trasfondo, mantienen una red indetectable y que, al permanecer abiertos, continuaban atrayendo y captando más víctimas inocentes.

Mediante esta disposición, las personas jurídicas son consideradas responsables de las infracciones penales relativas a la trata cuando sean cometidas en su beneficio por cualquier persona que, actuando a título individual o como parte de un órgano de la persona jurídica, ostente un cargo directivo en su seno, basado en un poder de representación de dicha persona jurídica, una autoridad para tomar decisiones en nombre de ella o una autoridad para ejercer control en su interior. También, son consideradas responsables de las infracciones penales relativas a la trata cuando la falta de supervisión o control por parte de una de las personas a que nos referimos en el párrafo anterior, haya hecho posible que una persona 
sometida a su autoridad cometa una de las infracciones penales relativas a la trata que contempla la directiva en beneficio de la persona jurídica.

Esta responsabilidad se establece sin perjuicio de las acciones penales que puedan emprenderse contra las personas físicas que sean autoras, inductoras o cómplices de alguna de las infracciones mencionadas; lo cual permite procesar y sancionar no solo a las personas físicas que hacen parte de la actividad criminal, sino a la persona jurídica que ampara y reviste de protección a tales personas para el desarrollo de este tipo delictivo. Así mismo, dentro del orden regional aparecen la "Comunicación de la Comisión al Parlamento Europeo, al Consejo, al Comité Económico y Social Europeo y al Comité de las Regiones - Estrategia de la UE para la erradicación de la trata de seres humanos (2012-2016)", la cual incluye medidas como la creación de unidades policiales nacionales especializadas en la trata de personas (en España llevan más de una década funcionando a nivel central y periférico en el Cuerpo Nacional de Policía, las UCRIF), la creación de equipos conjuntos de investigación europeos y la protección y apoyo a las víctimas. Allí se define la trata así:

[1]a trata de seres humanos es la esclavitud de nuestro tiempo. Con frecuencia las víctimas son captadas, transportadas o alojadas a la fuerza, mediante coacción o fraude en condiciones de explotación, incluidas la explotación sexual, el trabajo o los servicios forzosos, la mendicidad, las actividades delictivas o la extracción de órganos. Constituye una violación grave de la dignidad y la libertad de la persona y una forma de delincuencia grave, que a menudo tiene implicaciones que los países no pueden resolver con eficacia por separado.

La trata de seres humanos presenta muchas formas diferentes y evoluciona con los cambios socioeconómicos. Se centra en mujeres y hombres, niñas y niños en situaciones vulnerables. De acuerdo con las estimaciones disponibles de la Organización Internacional del Trabajo de junio de 2012 relativas al período 2002-2011, el número de víctimas del trabajo forzoso, incluida la explotación sexual, asciende a 20,9 millones a nivel mundial, con aproximadamente 5,5 millones de menores objeto de trata cada año. No obstante, se considera que esta estimación es conservadora.

La trata de seres humanos es una actividad delictiva lucrativa que genera beneficios por valor de varios miles de millones de euros.

En términos generales, asume la concepción ya estudiada del Protocolo de Palermo, pero advierte que el delito de trata constituye una violación grave de la dignidad y la libertad de la persona y constituye una forma de delincuencia grave, con un aspecto transnacional.

También, dentro de los instrumentos del orden regional europeo, se halla el “Convenio N 197 del Consejo de Europa sobre la "Lucha contra la trata de seres humanos" (2005), ratificado por España (2009), el cual trae, en su art. $4^{\circ}$, una definición de trata de seres humanos del siguiente tenor: 


\section{Artículo 4. Definiciones}

Para los fines del presente Convenio:

a) Por «trata de seres humanos» se entenderá el reclutamiento, transporte, transferencia, alojamiento o recepción de personas, recurriendo a la amenaza o uso de la fuerza u otras formas de coerción, el secuestro, fraude, engaño, abuso de autoridad o de otra situación de vulnerabilidad, o el ofrecimiento o aceptación de pagos o ventajas para obtener el consentimiento de una persona que tenga autoridad sobre otra, con vistas a su explotación. La explotación comprenderá, como mínimo, la explotación de la prostitución de otras personas u otras formas de explotación sexual, el trabajo o los servicios forzados, la esclavitud o las prácticas análogas a la esclavitud, la servidumbre o la extirpación de órganos;

b) El consentimiento de una víctima de la «trata de seres humanos» a la explotación pretendida, tal como se describe en la letra a) del presente artículo, será irrelevante cuando se utilice cualquiera de los medios a que hace referencia la misma letra a);

c) El reclutamiento, transporte, transferencia, alojamiento o recepción de un menor a efectos de su explotación se considerará «trata de seres humanos» aunque no se recurra a ninguno de los medios previstos en la letra a) del presente artículo;

d) Por «menor» se entenderá toda persona menor de dieciocho años;

e) Por «víctima» se entenderá toda persona física que sea objeto de trata de seres humanos según se define en el presente artículo.

Lo primero que debe resaltarse es que la noción guarda estrecha sincronía con la del art. 3 del Protocolo de Palermo, pero se diferencia en que el Convenio incluye el verbo rector 'reclutamiento'. Este último puede entenderse como sinónimo de captación; el diccionario de la lengua española, lo define como "acción o efecto de reclutar", y la palabra reclutar es definida, a su turno, como "reunir gente para un propósito determinado" y, por su parte, la voz captar significa "atraer a alguien", ganar la voluntad o el afecto de alguien. Sin embargo, pese a que podrían utilizarse como sinónimos, el reclutamiento implica mucho más que la simple captación, ambos términos sugieren atraer a una o varias personas, pero el primero implica unir esfuerzos para un propósito determinado, que se torna común, aunque sea mediante engaños; por su parte, la segunda, se configura con el solo hecho de atraer a una o varias personas, ganándose su voluntad o afecto. La mención expresa del verbo rector 'reclutar' amplía todavía más el abanico de situaciones susceptibles de calificarse como trata de seres humanos y con su tipificación expresa se salvan fronteras desdibujadas o grises del tipo penal en estudio.

La otra diferencia radica en los medios usados, pues el Protocolo de Palermo se refiere a la amenaza, la fuerza u otra forma de coacción y el Convenio de Varsovia alude a las amenazas, el uso de la fuerza u otras formas de coerción. Para aclarar el distingo, debe acudirse al diccionario de la lengua española que deslinda los significados de los términos coacción y coerción, al precisar que aquella es la 
"fuerza o violencia que se hace a alguien para obligarlo a que diga o ejecute algo", mientras que esta es la "presión ejercida sobre alguien para forzar su voluntad o su conducta". De los significados transcritos se puede observar que la palabra coacción presupone el uso de la fuerza o violencia, mientras que la palabra coerción omite esta implicación, bastando cualquier presión ejercida sobre otra persona, sin necesidad de violencia.

Las diferencias señaladas cobran importancia en el ámbito probatorio del delito de trata de seres humanos, dado que en el marco del Protocolo se debe probar el uso de la fuerza o violencia en cualquiera de sus modalidades para declarar la coacción; mientras que a la luz del Convenio basta con demonstrar la presión ejercida, sin demostrar que se usó cualquier tipo de fuerza o violencia. Esta prueba no representa grandes retos en los casos en que la fuerza o la violencia ejercidas son públicas, pero cuando ellas son íntimas se desarrollan en espacios privados o atacan la psique de la víctima, el debate probatorio se torna más complejo.

Ahora bien, dentro de los instrumentos jurídicos del orden regional americano, debe mencionarse la "Convención interamericana sobre tráfico internacional de menores" (OEA, 1994), que desarrolla el tema de la trata de niñas, niños y adolescentes, aprobada en el marco de la Organización de los Estados Americanos durante la "Quinta conferencia especializada interamericana sobre Derecho Internacional Privado", celebrada en México en 1994. La Convención entró en vigor el 15 de agosto de 1997 y establece una definición del delito de trata, en su art. 2 bajo el nombre de Tráfico internacional de menores. No obstante, es menester precisar que, para la época de esta Convención, aún no se habían decantado o especializado doctrinaria ni legalmente los términos usados para definir este evento criminal. Así, la palabra tráfico está tomada de su traducción literal del inglés Trafficking, pero, hoy, con los desarrollos doctrinarios alcanzados, la misma debe ser traducida al español como trata.

\section{Artículo 2}

Esta Convención se aplicará a cualquier menor que se encuentre o resida habitualmente en un Estado Parte al tiempo de la comisión de un acto de tráfico internacional contra dicho menor.

Para los efectos de la presente Convención:

a) "Menor" significa todo ser humano cuya edad sea inferior a dieciocho años.

b) "Tráfico internacional de menores" significa la substracción, el traslado o la retención, o la tentativa de substracción, traslado o retención, de un menor con propósitos o medios ilícitos.

c) "Propósitos ilícitos" incluyen, entre otros, prostitución, explotación sexual, servidumbre o cualquier otro propósito ilícito, ya sea en el Estado de residencia habitual del menor o en el Estado Parte en el que el menor se halle localizado. 
d) "Medios ilícitos" incluyen, entre otros, secuestro, consentimiento fraudulento o forzado, la entrega o recepción de pagos o beneficios ilícitos con el fin de lograr el consentimiento de los padres, las personas o la institución a cuyo cargo se halla el menor, o cualquier otro medio ilícito ya sea en el Estado de residencia habitual del menor o en el Estado Parte en el que el menor se encuentre.

Si bien este instrumento jurídico internacional regional se refiere solo a una franja de edad que va desde los cero a los 18 años de edad, es muy importante en la región americana para la lucha contra la trata de personas; esta Convención Interamericana trae en su definición tres elementos, a saber: actividad, propósitos ilícitos y medios ilícitos. Ellos guardan una relación estrecha con los ya analizados del Protocolo de Palermo, pero dejan entrever algunas diferencias: para la Convención, la actividad se refiere a la sustracción, al traslado o la retención de un menor -o a las tentativas de esas tres acciones-, lo cual suministra una tipificación más restrictiva que la del Protocolo de Palermo. A este instrumento se le debe reconocer el haber traído al debate regional americano este grave flagelo -aunque referido a menores de edad- en una época temprana -el año de 1994-, además de erigirse como un primer escalón en la lucha contra la trata de seres humanos en la región, que, según múltiples estudios, es el origen y destino predilecto de las organizaciones criminales que se dedican a ejecutar las acciones delictivas de trata de seres humanos.

Otro instrumento jurídico regional americano es la "Declaración interamericana para enfrentar la trata de personas", nombrada también como "Declaración de Brasilia" (OEA, 2014), la cual, a pesar de no brindar una definición de la trata, establece en su Declaración 1 que ese es un delito que viola los derechos humanos y atenta contra la libertad, la integridad física, la salud, la dignidad de las víctimas y de sus familias $\mathrm{y}$, añade, a los sectores más vulnerables de nuestras sociedades. Por primera vez, entonces, se reconoce la vulneración de derechos a las familias de las víctimas, que se erigen como víctimas secundarias de este delito; también se refiere, de forma expresa, a violaciones de los derechos humanos, en especial, la libertad y la dignidad humana -mencionados en otros instrumentos como vulnerados (Castro, 2015) - y, de modo novedoso, a la integridad física y la salud, que antes no habían sido tenidas en cuenta.

Por su parte, el "II Plan de Trabajo para Combatir la Trata de Personas en el Hemisferio Occidental-2015-2018" (OEA, 2014), surgido de la reunión antes mencionada, sostenida en Brasilia en 2014, precisa que la definición usada por tal Plan será la contenida en el Protocolo de Palermo, ya estudiada. Además, es menester indicar que la "Convención interamericana para prevenir, sancionar y erradicar la violencia contra la mujer" (OEA, 1994) o Convención de Belém do Pará, aunque no desarrolló una definición sobre trata de seres humanos, sí precisa que la misma debe ser entendida como violencia contra la mujer y, por ello, los Estados suscriptores tienen la obligación de proteger a las víctimas de trata, aun cuando no hayan suscrito los otros instrumentos jurídicos mencionados previamente. 
Ahora bien, en relación con las normas nacionales de España, Perú y Colombia, se hace a continuación referencia a la tipificación vigente sobre el delito de trata de seres humanos y se plasman algunas anotaciones relevantes para lo cual se emplean, como ya se indicó, los nombres propios dados al delito en estudio en cada una de esas legislaciones.

El instrumento jurídico español que contiene la definición vigente es el artículo 177 Bis del Código Penal, modificado por la Ley Orgánica 1 de 2015, normativa esa última mediante la cual el Estado español atendió sus compromisos internacionales y, en virtud de su artículo único, apartado 94, los numerales 1 y 4 del art. 177 Bis sufrieron modificaciones que entraron en vigencia el uno de julio de 2015 (Disposición Final Octava ibídem). El texto final vigente del artículo 177 Bis completo es el siguiente:

1. Será castigado con la pena de cinco a ocho años de prisión como reo de trata de seres humanos el que, sea en territorio español, sea desde España, en tránsito o con destino a ella, empleando violencia, intimidación o engaño, o abusando de una situación de superioridad o de necesidad o de vulnerabilidad de la víctima nacional o extranjera, o mediante la entrega o recepción de pagos o beneficios para lograr el consentimiento de la persona que poseyera el control sobre la víctima, la captare, transportare, trasladare, acogiere, o recibiere, incluido el intercambio o transferencia de control sobre esas personas, con cualquiera de las finalidades siguientes:

a) La imposición de trabajo o de servicios forzados, la esclavitud o prácticas similares a la esclavitud, a la servidumbre o a la mendicidad.

b) La explotación sexual, incluyendo la pornografía.

c) La explotación para realizar actividades delictivas.

d) La extracción de sus órganos corporales.

e) La celebración de matrimonios forzados.

Existe una situación de necesidad o vulnerabilidad cuando la persona en cuestión no tiene otra alternativa, real o aceptable, que someterse al abuso.

2. Aun cuando no se recurra a ninguno de los medios enunciados en el apartado anterior, se considerará trata de seres humanos cualquiera de las acciones enumeradas en el apartado anterior cuando se llevare a cabo respecto de menores de edad con fines de explotación.

3. El consentimiento de una víctima de trata de seres humanos será irrelevante cuando se haya recurrido a los medios indicados en el apartado primero de este artículo.

4. Se impondrá la pena superior en grado a la prevista en el apartado primero de este artículo cuando: 
a) se hubiera puesto en peligro la vida o la integridad física o psíquica de las personas objeto del delito;

b) la víctima sea especialmente vulnerable por razón de enfermedad, estado gestacional, discapacidad o situación personal, o sea menor de edad.

Si concurriere más de una circunstancia se impondrá la pena en su mitad superior».

5. Se impondrá la pena superior en grado a la prevista en el apartado 1 de este artículo e inhabilitación absoluta de seis a doce años, a los que realicen los hechos prevaliéndose de su condición de autoridad, agente de ésta o funcionario público. Si concurriere además alguna de las circunstancias previstas en el apartado 4 de este artículo se impondrán las penas en su mitad superior.

6. Se impondrá la pena superior en grado a la prevista en el apartado 1 de este artículo e inhabilitación especial para profesión, oficio, industria o comercio por el tiempo de la condena, cuando el culpable perteneciera a una organización o asociación de más de dos personas, incluso de carácter transitorio, que se dedicase a la realización de tales actividades. Si concurriere alguna de las circunstancias previstas en el apartado 4 de este artículo se impondrán las penas en la mitad superior. Si concurriera la circunstancia prevista en el apartado 5 de este artículo se impondrán las penas señaladas en este en su mitad superior.

Cuando se trate de los jefes, administradores o encargados de dichas organizaciones o asociaciones, se les aplicará la pena en su mitad superior, que podrá elevarse a la inmediatamente superior en grado. En todo caso se elevará la pena a la inmediatamente superior en grado si concurriera alguna de las circunstancias previstas en el apartado 4 o la circunstancia prevista en el apartado 5 de este artículo.

7. Cuando de acuerdo con lo establecido en el artículo 31 bis una persona jurídica sea responsable de los delitos comprendidos en este artículo, se le impondrá la pena de multa del triple al quíntuple del beneficio obtenido. Atendidas las reglas establecidas en el artículo 66 bis, los jueces y tribunales podrán asimismo imponer las penas recogidas en las letras b) a g) del apartado 7 del artículo 33.

8. La provocación, la conspiración y la proposición para cometer el delito de trata de seres humanos serán castigadas con la pena inferior en uno o dos grados a la del delito correspondiente.

9. En todo caso, las penas previstas en este artículo se impondrán sin perjuicio de las que correspondan, en su caso, por el delito del artículo 318 bis y demás delitos efectivamente cometidos, incluidos los constitutivos de la correspondiente explotación.

10. Las condenas de los jueces o tribunales extranjeros por delitos de la misma naturaleza que los previstos en este artículo producirán los efectos de reincidencia, salvo que el antecedente penal haya sido cancelado o pueda serlo con arreglo al Derecho español.

11. Sin perjuicio de la aplicación de las reglas generales de este Código, la víctima de trata de seres humanos quedará exenta de pena por las infracciones penales que 
haya cometido en la situación de explotación sufrida, siempre que su participación en ellas haya sido consecuencia directa de la situación de violencia, intimidación, engaño o abuso a que haya sido sometida y que exista una adecuada proporcionalidad entre dicha situación y el hecho criminal realizado.

Se debe resaltar el hecho de que los tipos vertidos en el art. 177 Bis aclaran los posibles sitios de comisión del delito, cuando indican en el numeral 1 "sea en territorio español, sea desde España, en tránsito o con destino a ella", con lo cual cubre de forma espléndida el abanico de posibilidades; pero, por otra parte, esas figuras carecen de una cláusula genérica para cobijar cualquier fin de explotación del ser humano como sería aconsejable, en atención a que así no habría fronteras grises por las cuales se deslizaran de forma impune los tratantes.

De igual forma, el legislador español omitió incluir las amenazas entre los medios utilizables para la comisión del delito de trata, por lo cual las acciones que tiendan a dar a entender con actos o palabras que se quiere hacer algún mal a alguien (según el diccionario de la lengua española), quedarían por fuera de la adecuación típica en estudio; con todo, hay autores que desprenden iguales consecuencias de la intimidación y de la amenaza, tratándolas como sinónimos; no obstante, teniendo en cuenta que intimidar significa "causar o infundir miedo", no parece correcto equipararlos.

En lo atinente al instrumento jurídico nacional de Perú, debe decirse la definición vigente del delito de trata de personas la brinda el Código Penal peruano en el Título IV, referido a los delitos contra la libertad, Capítulo I sobre la Violación de la libertad personal, arts. 153 y 153A, cuyos textos, con las modificaciones incorporadas por la Ley 28950 de 2007, son los siguientes:

Artículo 153.- Trata de personas.

El que promueve, favorece, financia o facilita la captación, transporte, traslado, acogida, recepción o retención de otro, en el territorio de la República o para su salida o entrada del país, recurriendo a: la violencia, la amenaza u otras formas de coacción, la privación de libertad, el fraude, el engaño, el abuso del poder o de una situación de vulnerabilidad, o la concesión o recepción de pagos o beneficios, con fines de explotación, venta de niños, para que ejerza la prostitución, someterlo a esclavitud sexual u otras formas de explotación sexual, obligarlo a mendigar, a realizar trabajos o servicios forzados, a la servidumbre, la esclavitud o prácticas análogas a la esclavitud u otras formas de explotación laboral, o extracción o tráfico de órganos o tejidos humanos, será reprimido con pena privativa de libertad no menor de ocho ni mayor de quince años.

La captación, transporte, traslado, acogida, recepción o retención de niño, niña o adolescente con fines de explotación se considerará trata de personas incluso cuando no se recurra a ninguno de los medios señalados en el párrafo anterior.

Artículo 153 A.- Formas Agravadas de la Trata de Personas. 
La pena será no menor de doce ni mayor de veinte años de pena privativa de libertad e inhabilitación conforme al artículo $36^{\circ}$ incisos 1, 2, 3, 4 y 5 del Código Penal, cuando:

1. El agente comete el hecho abusando del ejercicio de la función pública;

2. El agente es promotor, integrante o representante de una organización social, tutelar o empresarial, que aprovecha de esta condición y actividades para perpetrar este delito;

3. Exista pluralidad de víctimas;

4. La víctima tiene entre catorce y menos de dieciocho años de edad o es incapaz;

5. El agente es cónyuge, conviviente, adoptante, tutor, curador, pariente hasta el cuarto grado de consanguinidad o segundo de afinidad, o tiene a la víctima a su cuidado por cualquier motivo o habitan en el mismo hogar.

6. El hecho es cometido por dos o más personas.

La pena será privativa de libertad no menor de 25 años, cuando:

1. Se produzca la muerte, lesión grave o se ponga en inminente peligro la vida y la seguridad de la víctima.

2. La víctima es menor de catorce años de edad o padece, temporal o permanentemente, de alguna discapacidad física o mental.

3. El agente es parte de una organización criminal.

Esta definición se construyó con base en los lineamentos de los instrumentos jurídicos internacionales, dando lugar a un tipo penal amplio que abarca múltiples realidades y permite tipificar un gran número de conductas efectuadas por los tratantes. Dicha codificación, al incluir el delito de trata de personas desde el año 1991 con una definición tan descriptiva y comprensiva, sin que estuviera en vigor aún el Protocolo de Palermo, constituye un ejemplo de cómo los países latinoamericanos propenden por luchar y contener este flagelo desde mucho antes que la comunidad internacional se diera cuenta de la gravedad del mismo; esto obedece, es seguro, a que sus ciudadanos han sido víctimas de tales delitos.

Además, se debe resaltar que la Constitución Política de Perú (1993) eleva al rango constitucional la prohibición de la esclavitud, la servidumbre y la trata de seres humanos (art. 2, num. 24, lit. b), cosa que no ocurre en otras constituciones como la española.

Así mismo, el instrumento jurídico nacional de Colombia que brinda una definición de trata de personas es el Código Penal en su art. 188 A, modificado por la Ley 985 de 2005, "por medio de la cual se adoptan medidas contra la trata de per- 
sonas y normas para la atención y protección de las víctimas de la misma", cuyo texto es el siguiente:

Artículo 188A. Trata de Personas.

El que capte, traslade, acoja o reciba a una persona, dentro del territorio nacional o hacia el exterior, con fines de explotación, incurrirá en prisión de trece (13) a veintitrés (23) años y una multa de ochocientos (800) a mil quinientos (1.500) salarios mínimos legales mensuales vigentes.

Para efectos de este artículo se entenderá por explotación el obtener provecho económico o cualquier otro beneficio para sí o para otra persona, mediante la explotación de la prostitución ajena u otras formas de explotación sexual, los trabajos o servicios forzados, la esclavitud o las prácticas análogas a la esclavitud, la servidumbre, la explotación de la mendicidad ajena, el matrimonio servil, la extracción de órganos, el turismo sexual u otras formas de explotación.

El consentimiento dado por la víctima a cualquier forma de explotación definida en este artículo no constituirá causal de exoneración de la responsabilidad penal.

Esta redacción legal, adviértase, se acompasa mejor con los instrumentos internacionales al utilizar los mismos verbos rectores -captar, trasladar, acoger y recibir-. No se transcribe el verbo transportar, pero el mismo se deduce del significado literal del verbo trasladar porque, según el diccionario de la lengua española, trasladar es "llevar a alguien o algo de un lugar a otro" y transportar tiene idéntico significado, esto es, "llevar a alguien o algo de un lugar a otro"; así, la omisión de ese verbo rector no afecta en nada a la descripción típica del delito de trata.

En este caso el fin es la explotación, a cuyo efecto se entiende por tal:

el obtener provecho económico o cualquier otro beneficio para sí o para otra persona, mediante la explotación de la prostitución ajena u otras formas de explotación sexual, los trabajos o servicios forzados, la esclavitud o las prácticas análogas a la esclavitud, la servidumbre, la explotación de la mendicidad ajena, el matrimonio servil, la extracción de órganos, el turismo sexual u otras formas de explotación.

Como se ve, se utiliza una fórmula abierta en la redacción de la finalidad pretendida con la ejecución típica del delito de trata de personas cuando se emplea la expresión "u otras formas de explotación", con lo cual el tipo penal es abierto y evita que queden por fuera posibles formas, actuales o futuras, de explotación, tales como la utilización de las personas tratadas en la comisión de delitos, entre otros eventos.

A su vez, la Ley 1453 de 2011, adicionó los artículos 188 C y 188 D al Capítulo quinto referido a los delitos contra la autonomía personal del Título III de los delitos contra la libertad individual y otras garantías, cuyos textos son:

Artículo 6 . Tráfico de menores de edad: La Ley 599 de 2000 tendrá un artículo 188

C, el cual quedará así: 
Artículo 188 C. Tráfico de niñas, niños y adolescentes:

El que intervenga en cualquier acto o transacción en virtud de la cual un niño, niña o adolescente sea vendido, entregado o traficado por precio en efectivo o cualquier otra retribución a una persona o grupo de personas, incurrirá en prisión de treinta (30) a sesenta (60) años y una multa de mil (1.000) a dos mil (2.000) salarios mínimos legales mensuales vigentes. El consentimiento dado por la víctima o sus padres, o representantes o cuidadores no constituirá causal de exoneración ni será una circunstancia de atenuación punitiva de la responsabilidad penal. La pena descrita en el primer inciso se aumentará de una tercera parte a la mitad, cuando:

1. Cuando la víctima resulte afectada física o síquicamente, o con inmadurez mental, o trastorno mental, en forma temporal o permanente.

2. El responsable sea pariente hasta el tercer grado de consanguinidad, segundo de afinidad y primero civil del niño, niña o adolescente.

3. El autor o partícipe sea un funcionario que preste servicios de salud o profesionales de la salud, servicio doméstico y guarderías.

4. El autor o partícipe sea una persona que tenga como función la protección y atención integral del niño, la niña o adolescente.

Artículo $7^{\circ}$. La Ley 599 de 2000 tendrá un artículo nuevo 188 D, cuyo texto es el siguiente:

Artículo 188 D. Uso de menores de edad la comisión de delitos:

El que induzca, facilite, utilice, constriña, promueva o instrumentalice a un menor de 18 años a cometer delitos o promueva dicha utilización, constreñimiento, inducción, o participe de cualquier modo en las conductas descritas, incurrirá por este solo hecho, en prisión de diez (10) a diez y veinte (20) años.

El consentimiento dado por el menor de 18 años no constituirá causal de exoneración de la responsabilidad penal.

La pena se aumentará de una tercera parte a la mitad si se trata de menor de 14 años de edad.

La pena se aumentará de una tercera parte a la mitad en los mismos eventos agravación del artículo 188 C.

Como se ve, el artículo 188 D tipifica como delito el uso de menores de edad en la comisión de delitos, pero esto no implica que si además el menor es víctima de trata de personas, no se persiga a su tratante con las previsiones del artículo 188 A; igual situación ocurre con el reclutamiento forzado que algunos doctrinantes, de forma acertada, consideran como trata, figura ésta prevista en el Código colombiano como uno de los delitos contra las personas y bienes protegidos por el derecho internacional humanitario (art. 162), cuando se realiza dicha conducta sobre 
niños, niñas y adolescentes, para que participen - de forma directa o indirecta- en las hostilidades o acciones armadas con ocasión de la situación de violencia.

Esa postura doctrinal es apoyada por la Organización Internacional para las Migraciones, OIM -Misión en Colombia- (Beltrán, 2006), cuando expone que

[d]e acuerdo con la Ley 985 de 2005, en la que la trata de personas se configura con el traslado y la explotación -en los casos en que se presente traslado de personas menores de dieciocho años con un fin de explotación vinculado a la situación de violencia- se está frente al delito de trata de personas.

Es importante resaltar que Colombia, desde el año 1980, tipificó la trata de mujeres y de menores en el Código Penal. Aunque entonces la figura punible estaba referida solo a víctimas que fueran mujeres y niños, dejando por fuera otras realidades que, al parecer, no eran tan notorias en esa época, referidas a la trata de hombres; esto fue solucionado mediante la Ley 360 de 1997 que hizo extensivo el delito de trata de personas a víctimas de ambos sexos, bien sean adultos, menores o de la tercera edad, al precisar que el sujeto pasivo de la trata son todas las personas. Con todo, ninguna de esas tipificaciones, ni la inicial ni la posterior, hacían referencia al fenómeno de la trata como se le concibe hoy sino solo a la eventualidad de que las personas tratadas tuvieran por destino el ejercicio de la prostitución.

Con la temprana tipificación de 1980, la primera en el tiempo de las tres legislaciones nacionales aquí comparadas, Colombia se erige como pionera y abanderada en las legislaciones iberoamericanas y en los instrumentos jurídicos internacionales y regionales revisados, al consagrar el delito de trata de personas, así en un principio se haya tipificado solo como conducta punible la realizada sobre mujeres y menores, y ya en 1997 se hubiera extendido a cualquier persona. Por supuesto, esto demuestra que en Colombia este flagelo atacaba a sus mujeres y niños desde épocas muy tempranas, antes de 1980, lo que obligó a tipificar esta conducta con el fin de sancionar a sus actores. La trata de seres humanos no es, pues, un delito de reciente surgimiento, sino que es un evento criminal que atenta contra los derechos del ser humano, que ocurre hace décadas y precede -por muchos años- a la toma de conciencia por parte de los Estados y su posterior consagración en instrumentos jurídicos internacionales, regionales o nacionales.

También, se debe exaltar la consagración constitucional de la prohibición de la esclavitud, la servidumbre y de la trata de seres humanos en todas sus formas, cuando en el art. 17 la Constitución Política colombiana de 1991, se eleva a rango constitucional tal prohibición -dos años antes de la consagración constitucional peruana-. Con lo cual Colombia vuelve a liderar la prohibición de la trata de seres humanos en todas sus formas, erigiéndola como carta de navegación para cualquier legislación interna y para la creación e implantación de políticas estatales en contra de tal flagelo.

Así las cosas, toda esta temprana y prolífica legislación permite concluir que dicha legislación es pionera en la tipificación y el tratamiento del delito, y siempre 
ha demostrado un ingente deseo por sancionar, prevenir y proteger a las víctimas de este flagelo, que de forma lastimosa golpea con dureza a las poblaciones menos favorecidas. No obstante, estos esfuerzos teóricos y legislativos no van acompañados con apoyos económicos significativos que ayuden a consolidar las políticas estatales frente a esta actividad criminal lesiva de los derechos humanos, en especial de la dignidad humana.

\section{Algunas definiciones emitidas por otros organismos.}

Luego de revisadas las nociones contenidas en los instrumentos estudiados, debe ahora hacerse un breve recorrido por las construcciones producto de diversos pronunciamientos originados en otras instituciones.

En efecto, para la Asociación para la Prevención, Reinserción y Atención de la Mujer Prostituida-APRAMP (Guerrero, s. f.), la trata de seres humanos:

[s]upone una transacción con la persona entendida como un objeto (la persona es el objeto de la transacción), que exige además de un movimiento -que puede ser licito o ilícito- unos fines de explotación de las personas víctimas de la trata, explotación que puede ser sexual, laboral, esclavitud, servidumbre o extracción de órganos.

Así mismo, para la Agencia de la ONU para los Refugiados-ACNUR (s. f.), la trata

[c]onsiste en utilizar, en provecho propio y de un modo abusivo, las cualidades de una persona. Para que la explotación se haga efectiva los tratantes deben recurrir a la captación, el transporte, el traslado, la acogida o la recepción de personas. Los medios para llevar a cabo estas acciones son la amenaza o el uso de la fuerza u otras formas de coacción, el rapto, fraude, engaño, abuso de poder o de una situación de vulnerabilidad. Además se considera trata de personas la concesión o recepción de pagos o beneficios para obtener el consentimiento de una persona que tenga autoridad sobre otra, con fines de explotación. La explotación incluirá, como mínimo, la explotación de la prostitución ajena u otras formas de explotación sexual, los trabajos o servicios forzados, la esclavitud o las prácticas análogas, la servidumbre o la extracción de órganos.

A su turno, Save the Children España (2008) precisa:

[u]n niño o niña víctima de trata es cualquier persona menor de 18 años que es captada, trasladada, escondida o recibida con fines de explotación desde dentro o fuera de un país; exista o no coacción, engaño, abuso de autoridad o cualquier otro tipo de abuso.

También, la Consejería de Justicia e Interior de la Junta de Andalucía (Navarro, s.f.), indica que:

Basados en la definición inicial de trata proporcionada por el Protocolo de Palermo, el propósito o resultado de explotación de niños y niñas puede incluir: 
1. Explotación sexual (incluyendo la explotación por prostitución de otros u otras formas de explotación sexual - así como la pornografía y los matrimonios forzosos).

2. Trabajos o servicios forzosos.

3. Esclavitud o alguna práctica similar a la esclavitud, servilismo o

4. Extirpación de órganos.

Y continúa:

Es importante anotar que el Protocolo de Palermo no menciona específicamente el reclutamiento de niños para trabajos arriesgados o adopciones ilegales. De cualquier modo, de acuerdo con otros instrumentos legales internacionales vinculados, los Estados deben tomar acciones para detener el empleo de cualquier persona por debajo de los 18 años en trabajos arriesgados y la adopción que viole la ley internacional de adopción (respectivamente, la Convención de la OIT No.182 en la Prohibición y la Acción inmediata por la Eliminación de las Peores Formas de Trabajo Infantil y la Convención de la Haya sobre la Protección de niños y niñas y la Cooperación en relación a la Adopción entre diferentes Países).

Muchos niños y niñas son víctimas de trata en el mundo con fines de explotación sexual, adopción ilegal, utilización de los niños y niñas para pedir limosna, para cometer delitos menores y otras formas de trabajo forzoso.

Para la ONU (2000), la definición a usar es la establecida en el Protocolo para prevenir, reprimir y sancionar la trata de personas, en especial mujeres y niños, que complementa la Convención de las Naciones Unidas contra la Delincuencia Organizada Transnacional, suscrito en Palermo en el año 2000, impulsado por tal organización y que fue examinado antes.

De igual forma, la UNICEF (2007), estima que la trata de personas

[e]s una forma multidimensional de explotación que implica diferentes tipos de explotación incluidas las violaciones de derechos humanos y libertades fundamentales, el trabajo forzoso, la servidumbre por deudas, la explotación de migrantes y trabajadores migratorios, la explotación laboral y sexual, la violencia y discriminación contra las mujeres y la explotación sexual, laboral y de otro tipo, de niños, niñas y adolescentes. Pero además la trata es en sí misma una forma de explotación. La trata de personas se produce en un escenario de circunstancias interrelacionadas que aumentan la vulnerabilidad de los individuos y crean las condiciones que propician que ocurra. Este escenario incluye diferentes dimensiones: la pobreza, la discriminación por razón de género, las situaciones de conflicto, las economías en transición, las violaciones de los derechos humanos, la corrupción, las políticas de migración, las condiciones del mercado laboral, la falta de ciudadanía y la demanda.

Pero, después, acoge como propio y desarrolla el concepto acuñado por el Protocolo de Palermo. A su turno, la OEA (OAS, por su sigla en inglés) (2005), propone una noción de trata de personas que, en su sentir, es adecuada para el derecho penal, al precisar que con la misma se establece con claridad la naturaleza del 
crimen, evitando usar tantos elementos descriptivos y confusos. Por ello, la "trata de personas" significa "el reclutamiento, el transporte, la transferencia, acogida o el recibo de personas, por cualquier medio, para el trabajo o servicios forzado, la esclavitud, prácticas similares a la esclavitud, la servidumbre o la remoción de órganos".

También, pregona que:

[c]onforme a esta definición del derecho penal, se obtendría con mayor facilidad el enjuiciamiento y no se abrirían a procesos por imprecisión de parte de los demandados. La definición propuesta elimina la necesidad para demostrar que las amenazas, la coacción, el fraude, etc., son usadas para introducir a una persona en una situación de trata. El 'medio' para mover a alguien a una situación de trata no es importante, pero el proceso de movilizar gente de un lugar a otro para retenerlos, someterlos a trabajo forzados o a la esclavitud son esenciales en este crimen. Finalmente, la definición suprime todos los términos indefinidos y ambiguos, dejando sólo los crímenes que son definidos en la ley internacional y en la ley domestica de muchos países. La definición de derecho penal es bastante amplia para cubrir toda y cada forma de la trata - desde la trata para la mendicidad forzada o el trabajo doméstico hasta la trata en la prostitución o el trabajo agrícola forzado.

A su vez, el Center for Human Rights \& Humanitarian Law de la American University Washington College of Law (2000), hace unas apreciaciones muy interesantes y brinda una construcción conceptual propia al precisar:

[1]a trata de personas es básicamente el movimiento de personas a situaciones donde son vulnerables a ser sometidas a trabajo forzoso, esclavitud, condiciones similares a la esclavitud, la servidumbre por deudas, u otro tipo de servidumbre. Los traficantes recurren a diferentes medios para obtener control sobre sus víctimas. Los más inteligentes no utilizan la fuerza, sino la manipulación psicológica para hacer creer a la persona que él o ella van simplemente a emigrar para realizar un trabajo, para casarse, o para asistir a la escuela. Otros traficantes acuden a técnicas de control o amenazas de cometer daño.

Incluso, el Informe sobre la trata de personas confeccionado por el Departamento de Estado de los EE.UU. (2011) contiene una definición de este fenómeno, así:

En los últimos 15 años, los términos "trata de personas" y "trata de seres humanos" se han usado como términos generales que definen las actividades en las que una persona obtiene o mantiene trabajos o servicios realizados por otra persona por medios forzosos. La Ley de Protección de las Víctimas de Trata del año 2000 (Ley pública 106-386), y sus enmiendas (TVPA, por sus siglas en inglés), y el Protocolo para Prevenir, Reprimir y Sancionar la Trata de Personas, especialmente Mujeres y Niños, que complementa la Convención de las Naciones Unidas contra la Delincuencia Organizada Transnacional (el Protocolo de Palermo) describen este servicio obligatorio con diversos términos diferentes, incluidos servidumbre involuntaria, esclavitud o prácticas similares, servidumbre por deudas y trabajo forzoso. 
Según el Protocolo de las Naciones Unidas para prevenir, reprimir y sancionar la trata de personas, especialmente mujeres y niños (Protocolo de Palermo) y la TVPA, las personas pueden ser víctimas de la trata independientemente de si nacieron en condiciones de servidumbre o fueron trasladadas a la situación de explotación, ya sea porque alguna vez aceptaron trabajar para un tratante de personas, o por haber participado en un delito como consecuencia directa de ser víctimas de la trata. El núcleo de este fenómeno son las múltiples formas de esclavitud, no las actividades relacionadas con el traslado internacional.

Por su parte, en los Informes sobre la Trata de Personas efectuados por el Departamento de Estado de los EE.UU. (2012; 2013; 2014; 2015), se indica:

'Trata de personas', 'trata de seres humanos' y 'esclavitud moderna' son términos generales para referirse a los actos de reclutar, albergar, transportar, suministrar $\mathrm{u}$ obtener una persona para obligarla a realizar trabajos forzosos o actos de comercio sexual mediante el uso de fuerza, fraude o coacción.

La trata de personas puede incluir, pero no necesariamente, el traslado. Se puede considerar que una persona es víctima de trata independientemente de si nació en el estado de servidumbre, fue explotada en su propia ciudad, fue transportada a una situación de explotación, consintió previamente en trabajar para un tratante o participó en un delito como resultado directo de la trata. En el núcleo de este fenómeno está el objetivo del tratante de explotar y esclavizar a sus víctimas y la multitud de prácticas de coacción y engaño que utilizan para ello.

De igual forma, para la Fundación Camino a Casa (FCC), la trata de personas

[e]s comprendida como un acto que va contra la voluntad de la persona, donde la misma pierde la libertad de decisiones y esto puede ocurrí de manera legal o ilegal, las personas adultas, adolescentes y niños son engañadas y luego explotadas laboralmente y/o sexualmente.

Esta misma organización precisa que la explotación de un ser humano consiste en "[o]btener o utilizar en beneficio propio de forma abusiva, las cualidades, el trabajo, los servicios o el cuerpo de una persona, de un suceso o de una circunstancia cualquiera".

Así las cosas, de todas las definiciones anteriores se puede concluir que, aunque hay nociones tanto doctrinarias como legales muy bien encaminadas y elaboradas, hay otras que permiten confeccionar tipos penales cerrados al hacer una descripción restrictiva de la trata de seres humanos, dejando por fuera situaciones o elementos claves, cuando no circunscribiéndola solo a algunos aspectos de la explotación, casi siempre referidos al aspecto sexual o laboral.

Por ende, puede afirmarse que la definición contenida en el art. $3^{\circ}$ del Protocolo de Palermo constituye una gran construcción conceptual, amplia y comprensiva de múltiples eventos constitutivos de trata de personas, que se puede mantener actualizada, con pequeños ajustes, a las realidades cambiantes de este fenómeno, donde la legislación sobre el tema rápidamente se queda atrás con relación a las 
nuevas invenciones y prácticas utilizadas por las organizaciones delincuenciales dedicadas a este flagelo.

\section{La definición propuesta para el delito de trata de seres humanos.}

Con base en lo estudiado (Castro, 2015. p. 41), debe formularse una noción que supere las falencias detectadas en las definiciones legales y doctrinarias estudiadas, con el humilde propósito de impulsar a los organismos internacionales, a los legisladores nacionales y a los doctrinantes, hacia el siguiente paso en los desarrollos doctrinarios y legales de esta actividad criminal. La redacción que se somete a debate es la siguiente:

Será penado como reo de trata de seres humanos el que en territorio nacional, desde territorio nacional, en tránsito por el territorio nacional o con destino al territorio nacional, promueva, induzca, constriña, facilite, financie, favorezca, colabore, coordine, oriente, asesore, participe, realice, ejecute por sí o por otra persona, ordene ejecutar o genere de alguna forma las condiciones propicias para desarrollar la captación, el reclutamiento, el transporte, el traslado al interior de un país o entre diversos países, la acogida, la recepción, la retención, el intercambio o la transferencia de control sobre seres humanos, recurriendo a cualquier forma de violencia, amenaza, intimidación, uso de la fuerza física o psicológica, uso de cualquier otro medio de presión, coacción o coerción, engaño, fraude, privación o restricción de la libertad, secuestro, rapto, abuso de poder, de una situación de superioridad, de necesidad o de vulnerabilidad, ofrecimiento, concesión o recepción de pagos o beneficios de cualquier índole, para obtener el consentimiento de una persona que tenga autoridad sobre otro ser humano o posea control sobre la víctima, o mediante cualquier otro medio o forma, con el fin de obtener, directa o indirectamente, para sí o para un tercero, un provecho o beneficio de cualquier índole, con fines de explotación.

Esta explotación incluirá, como mínimo, la negociación de cualquier índole en donde se tenga como mercancía o bien negociable a un ser humano, la explotación de la prostitución ajena u otras formas de explotación sexual incluyendo la pornografía, la imposición de trabajos o servicios forzados, la mendicidad, cualquier forma de explotación laboral, la esclavitud, las prácticas análogas a la esclavitud, la servidumbre, incluyendo la servidumbre por deudas o cualquier otra forma de servidumbre, la extracción de órganos o tejidos humanos, la explotación para realizar actividades delictivas, el matrimonio forzado o servil, el reclutamiento forzado, la adopción ilegal, la venta de niños, el embarazo forzado, el vientre en alquiler forzado, o cualquier otra forma de explotación.

El consentimiento de la víctima de trata de seres humanos será irrelevante cuando se haya recurrido a alguno de los medios indicados antes.

La realización de cualquiera de las actividades enunciadas cuya víctima sea un niño con fines de explotación se considerará como trata de seres humanos, incluso cuando no se recurra a ninguno de los medios enunciados antes.

Por 'niño' se entenderá toda persona menor de 18 años. 
Existe una situación de necesidad o vulnerabilidad cuando la víctima no tenga otra alternativa que sea para ella real, accesible o aceptable, que someterse al abuso o explotación.

Sin perjuicio de la aplicación de las reglas generales de derecho penal, la víctima de este delito quedará exenta de pena por las infracciones penales que haya cometido en la situación de explotación sufrida, siempre que su participación en ellas haya sido consecuencia directa de los medios utilizados para cometer la trata y que exista una adecuada proporcionalidad entre la situación en que se encontraba la víctima y el hecho criminal realizado. A su vez, las personas jurídicas serán consideradas responsables de la trata de seres humanos, cuando estas infracciones sean cometidas en su beneficio por cualquier persona que, actuando a título individual o como parte de un órgano de la persona jurídica, ostente un cargo directivo en su seno, basado en:

a) un poder de representación de dicha persona jurídica;

b) una autoridad para tomar decisiones en nombre de dicha persona jurídica, o

c) una autoridad para ejercer control dentro de dicha persona jurídica.

También, serán consideradas responsables cuando la falta de supervisión o control por parte de una de las personas antes referidas, haga posible que una persona sometida a su autoridad cometa una de las infracciones contempladas como trata de seres humanos en beneficio de la persona jurídica. La responsabilidad de las personas jurídicas se entenderá sin perjuicio de las acciones penales que puedan emprenderse contra las personas físicas que sean autores, inductores, partícipes o cómplices de alguna de las infracciones establecidas como trata de seres humanos.

En relación con los castigos, dado que entran en la esfera propia de los estados soberanos, se plantea hacer una referencia expresa a que, con fines disuasorios, las penas y puniciones sean tan fuertes y gravosas que con ellas los actores no permanezcan impunes; así mismo, los procesos de judicialización de los responsables deben ser tan eficientes y eficaces en su proceder, que eviten las demoras procesales innecesarias.

\section{Conclusiones}

La trata de seres humanos es una actividad criminal de gran relevancia mundial que, por su naturaleza pluriofensiva, vulnera de forma grave múltiples derechos de las víctimas inmediatas y de sus familias -víctimas secundarias-, entre los cuales se pueden citar los derechos humanos, la dignidad humana, la libertad en muchas de sus diversas modalidades, según el tipo de explotación -sexual, de locomoción, de escogencia de profesión o empleo, de disposición de su cuerpo-, el libre desarrollo de la personalidad, la indemnidad y el pudor sexuales, la vida, la honra, la libre autodeterminación, la salud física y mental, la seguridad laboral y la salud pública, etc.

Ahora, si la reflexión se centra en los dos ejes orientadores de este trabajo, se debe indicar que, frente al primero, el mismo se ocupa del nombre que se le da al 
delito porque de él depende la forma como el estado debe asumir sus retos; en este sentido, la denominación 'trata de seres humanos' brinda una panorama de protección más amplio, al preservar todos los momentos de existencia de un miembro de la especie biológica humana, esto es, desde su concepción hasta su muerte, con lo cual se obvian discusiones sobre la aplicabilidad de este delito a ciertos casos en donde un ser humano, según el régimen legal del país de que se trate, aún no ha cumplido con todos los requisitos legales para ser reconocido como persona -titular de derechos y obligaciones- $y$, con ello, delimitar esas fronteras grises de forma apropiada, para evitar que los tratantes consigan impunidad en algunas de sus actividades delictivas, sobre todo si se hace referencia a situaciones como la trata de infantes, o de concebidos en el vientre materno, o de victimizar a una mujer con el fin de hacerla procrear obligatoriamente, entre otros muchos casos posibles.

El segundo eje sobre el que giró este trabajo tuvo un desarrollo más extenso, debido no solo a lo prolífico de los instrumentos jurídicos internacionales, regionales y nacionales que definen esta actividad criminal, sino a las diversas nociones doctrinales estudiadas. Para ello, se definieron las diversas clases de trata de seres humanos y se trabajaron los elementos constitutivos del delito, para lo cual se emplearon las definiciones contenidas en el "Protocolo para prevenir, reprimir y sancionar la trata de personas, especialmente mujeres y niños", que complementa la "Convención de las Naciones Unidas contra la delincuencia organizada transnacional" y, así, se revisaron los desarrollos de los elementos constitutivos mencionados, a saber: actividad, medios comisivos y finalidad de explotación.

También, se examinaron las diversas nociones contenidas en otros instrumentos jurídicos internacionales, regionales y nacionales, amén de las emitidas por otros organismos, para arribar a una propuesta con la cual se pretende suplir algunas falencias detectadas por la doctrina y superar las llamadas zonas grises que generan una grave e indeseable impunidad a ciertos tratantes que aprovechan esas grietas legales, las cuales deben eliminarse al brindar una definición comprensiva de una pluralidad de realidades presentes y futuras de esta grave actividad delincuencial.

Adicional a lo ya dicho, a los fines de este artículo académico se puede concluir que, transcurridos 16 años desde la publicación del Protocolo de Palermo, no todos los países han cumplido con sus obligaciones, pero, en la actualidad, con las descripciones típicas estudiadas de los tres países revisados, a saber, España, Colombia y Perú, se puede colegir que los mismos cumplen con algunas de las obligaciones emanadas del mismo. Sin embargo, es menester lograr que estos países velen por un cumplimiento efectivo de los mandatos del Protocolo, porque todo indica que se conforman con transponer sus postulados sin brindar unos desarrollos profundos o efectivos.

En muchos casos, como en el colombiano, el gobierno nacional se contenta con repetir -año a año- las mismas actuaciones frente a la trata de seres humanos y crea organismos sin recursos para actuar, como el Comité interinstitucional para la lucha contra la trata de personas, lo cual ha generado que la calificación dada 
a Colombia por el Departamento de Estado de los Estados Unidos, desde 2014, haya pasado de nivel 1: país que cumple plenamente con las normas mínimas para la eliminación de la trata de personas, al nivel 2: país que no cumple plenamente con las normas mínimas para la eliminación de la trata de personas, y esto bajo las impávidas miradas gubernamentales. Desde luego, esta calificación influye en el discurso teórico de protección inadecuada de las víctimas e impide que el Estado colombiano se beneficie de las ayudas del gobierno estadounidense.

Ahora bien, para entender de manera adecuada el delito de trata de seres humanos hay un gran camino que recorrer y se presenta un sinnúmero de desafíos (Castro, 2015), entre los que pueden mencionarse: 1. Es necesario sensibilizar a la sociedad en torno a las realidades a las cuales están expuestas las víctimas de trata y en torno a la realidad del delito de trata de seres humanos en sí mismo, todo ello con el fin de velar por la prevención del delito y, si esto falla, por lo menos, con propender por una detección temprana de los posibles casos de trata de seres humanos. 2. Se deben contrarrestar los esfuerzos de las organizaciones delincuenciales para aumentar sus redes de trata de seres humanos, las cuales invierten grandes sumas de dinero con la certeza de que podrán recuperar con creces tales inversiones, sin correr mayores riesgos, haciéndoles más onerosa su actividad delincuencial. 3. Debe brindarse un tratamiento integral a las víctimas, mediante políticas de protección, ayuda y tratamiento adecuado y efectivo, que propendan por una reintegración social completa con la cual puedan superar las graves secuelas que les haya dejado el ilícito al que fueron sometidas. 4. Debe trabajarse en la eliminación de los grandes mitos, estigmas y prejuicios tejidos en torno a la trata de seres humanos. 5. Es muy importante empoderar a las personas que están en situación de vulnerabilidad y podrían ser víctimas; igual debe hacerse con aquellas que son o fueron víctimas de este delito.

Adicional a lo anterior, es menester seguir la ruta que dibuja la doctrina especializada, basada en el estudio de las realidades que genera la ejecución típica del delito de trata de seres humanos, para profundizar en las realidades subyacentes de este delito y proponer políticas de eliminación de sus causas. No se puede pretender que las soluciones sean obtenidas de forma mágica desde la óptica del derecho penal, dado que este pretende sancionar conductas y desestimular su repetición, pero, para erradicar este flagelo, hay que atacar las causas detectadas por un trabajo serio y multidisciplinario; además, se deben mejorar las condiciones de las poblaciones con mayor riesgo y, sobre todo, es necesario empoderar a estas poblaciones y a las víctimas de este delito, para que puedan resistir a las tramas delincuenciales que pretenden captarlas o mantenerlas en un ciclo de explotación.

Por supuesto, es muy importante continuar con las investigaciones académicas y situacionales sobre este delito, en orden a conocer nuevas formas de trata y, por supuesto, mantenerse a la par de los desarrollos efectuados por los tratantes, para enfrentarlos con políticas públicas adecuadas y un manejo interdisciplinario que incluya el apoyo invaluable de las ONG, cuyo fin es la erradicación de este flagelo. 


\section{Referencias}

Acfilosofia. (s. f). Ser Humano y Persona. Recuperado de http:/ / www.acfilosofia. org / materialesmn / filosofia-y-ciudadania-3013/el-ser-humano-persona-ysociedad/182-ser-humano-y-persona

Agencia de la ONU para los Refugiados - ACNUR. (s.f). La Trata y el Tráfico de Personas. Recuperado de http://www.acnur.org/t3/que-hace/proteccion/ trata-y-trafico-de-personas /

Alva, M. (2008). La Concepción de la Personalidad. Psicología de la Personalidad. Recuperado de http:/ / psicologiadelapersonalidad.blogspot.com.co/2008/03/ la-concepcion-de-la-personalidad.html.

Beltrand, D. (2006). Dimensiones de la Trata de Personas en Colombia. BogotáColombia: Panamericana Formas e Impresos S. A.

Betancur, M. (2010). Persona y Máscara. Revista Praxis Filosófica de la Universidad de Caldas. Nueva serie (30), 127-143. Recuperado de http:/ / psicologiadelapersonalidad.blogspot.com.co/2008/03/la-concepcionde-la-personalidad.html.

Cabanillas, A. (1993). Comentarios a los artículos 17 a 41. En M. Albadalejo; S. Díaz (Dir.). Comentarios al Código Civil y Compilaciones Forales (T. I, 2 ed., Vol. 3). Madrid: Edersa.

Castro, A. (s.f.). Los delitos de trata de personas y tráfico ilícito de migrantes como nuevas formas de esclavitud del siglo XXI (Tesis doctoral inédita, Universidad de Granada España).

Castro, A. (septiembre, 2015). El Delito de Trata de Personas: Una nueva forma de Esclavitud del Siglo XXI. Sensibilización global de la necesidad de Estrategias Internacionales efectivas para la para la Prevención y Promoción de tal Delito y la Protección, Asistencia, Apoyo y Tratamiento efectivo a las víctimas, que permita una ayuda adecuada y su reinserción social efectiva que les permita superar las secuelas que en ellas haya dejado el ilícito al que fueron sometidas. Trabajo presentado en el I Congresso Roraimense De Direitos Humanos E Direito Internacional Instituto De Ciencias Jurídicas (Icj)-Universidad Federal De Roraima. Cuaderno de Resumos, Año I, (1), 41 y ss. Recuperado de http: / / ufrr.br/ cdhdi / index.php/ 2015-07-14-14-38-29 / caderno-de-resumosdo-i-congreso

Castro, A. (octubre, 2015). Las realidades y desafíos del tratamiento del delito de trata de seres humanos como una forma grave de violación de los derechos humanos, mediante la explotación sexual de mujeres y menores. Trabajo presentado en el Congreso Internacional On-Line: La Prostitución desde una Perspectiva de los Derechos Humanos: Nuevos Desafíos para el Siglo XXI, de la Universitat De Les Illes Balears. Recuperado de http://www.uibcongres.org/prostitucion15/ programa.es.html, http://www.uibcongres.org/prostitucion15/ponencia. es.html?mes=3\&ordpon $=25$ 
Center for Human Rights \& Humanitarian Law. (s. f). El Protocolo de la ONU sobre la Trata de Personas: Un Enfoque Imperfecto. Recuperado de http: / / rightswork.org / wp-content / uploads / 2011 / 09 / Documento-deDiscusion-1.pdf

Código Civil (1887). Congreso de la República de Colombia. Colombia. Recuperado de http: / / www.secretariasenado.gov.co/ senado/basedoc/codigo_civil.html

Comisión Europea. (2012). Comunicación de la Comisión al Parlamento Europeo, al Consejo, al Comité Económico y Social Europeo y al Comité de las RegionesEstrategia de la UE para la erradicación de la trata de seres humanos (20122016) /* COM/2012/0286 final */, Recuperado de http://eur-lex.europa.eu/ legal-content/ES / ALL/ ?uri=CELEX\%3A52012DC0286

Comisión Interamericana de Mujeres -[CIM] de la Organización de Estados Americanos - OEA, Organización Internacional para las Migraciones -OIM, Instituto Nacional de Migración e Instituto Nacional de las Mujeres. (2006). Trata de Personas - Aspectos Básicos. México. Recuperado de http:/ / www.oas. org/atip/ reports / trata.aspectos.basicos.pdf

Consejo Argentino para la Información y el Desarrollo de la Biotecnología. (s. f). Proyecto genoma Humano. Recuperado de http://www.porquebiotecnologia. com.ar $/$ index.php?action $=$ cuaderno\&opt $=5 \&$ tipo $=1 \&$ note $=55$

Consejo de Europa. (2005). Convenio N 197 del Consejo de Europa sobre la Lucha contra la Trata de Seres Humanos. Recuperado de http://www.accem.es/ ficheros / documentos/pdf_trata/Convenio_Consejo_de_Europa.pdf

Consejo Permanente de la Organización de los Estados Americanos -[OEA]. Comisión de Seguridad Hemisférica. (2014) Resolución OEA/Ser.K/ XXXIX.4 RTP-IV/doc.5/14 rev. 1 de 5 de diciembre de 2014. Recuperado de http: / / www.oas.org/dsp/espanol/cpo_trata_resoluciones.asp.

Cruz, J. (2011). La noción de "persona" en la tradición clásica. Recuperado de http://www.leynatural.es/2011/08/02/que-es-persona/, también en http://www.significados.com/persona/.

De Aránzazu, M. (2007, Julio). El Concepto de persona en el derecho civil ante una antropología dual. Revista de Filosofía Thémata, (39), 269-279. Recuperado de http: / / institucional.us.es / revistas/themata /39/art34.pdf

Discovery Channel (2016). Trata de Mujeres: De Tenancingo a Nueva York. Disponible en https: / / www.youtube.com/watch?v=dN7Ur1uV6vo.

Fernández, P. (2012). Una aproximación práctica a la lucha contra la trata de seres humanos en España. En S. García y otra. La Trata de Seres Humanos (pp. 99-150). Madrid. España: Centro de Estudios Políticos y Constitucionales.

Fernández, C. (s. f). ¿Qué es ser persona para el Derecho? Portal de Información y Opinión Legal de la Pontificia Universidad Católica del Perú-DIKE. Recuperado de http://dike.pucp.edu.pe/bibliotecadeautor_carlos_fernandez_cesareo/ articulos/ba_fs_13.PDF 
Fondo de las Naciones Unidas para la Infancia -UNICEF, Organización Internacional para las Migraciones -OIM. (2007). Trata de Personas y Tráfico Ilícito de Migrantes en México y América Central-Guía Normativa. Recuperado de http: / / www.unicef.org/lac/Guia_trataFINAL(3).pdf. Panamá: Panamá

Fundación Camino a Casa (FCC). Recuperado de http://www.fcc.org.bo/index. $\mathrm{php} / \mathrm{men}$-proyectos/men-ninos/ community-layout1383624625/120-la-tratay-trafico-de-personas-es , http://www.fundacioncaminoacasa.org/ http:// www.fundacioncaminoacasa.org/interiores/info.html.

Global Rights. (2005). Guía Anotada del Protocolo Completo de la ONU contra la Trata de Personas. Recuperado de http://www.oas.org/atip/Reports/Annot_Prot_ SPANISH.pdf.

Guerrero, C. (s.f.). Concepto de trata de seres humanos para la explotación sexual. Recuperado de www.apramp.org http:/ / www.apramp.org/noticia.asp?id=500.

Macanás, G. (2013). Efectos y Defectos del artículo 30 del Código Civil. Aspectos relativos a la muerte perinatal inmediata. Revista para el Análisis del Derecho InDret. (4), 5-42. Recuperado de www.indret.com http://www.indret.com/ pdf/1009_es.pdf

Navarro, L.; Alconada de los Santos, M. \& Rubio, M. (s. f). Materiales Formativos: Asilo y Protección Internacional. La Situación de las personas refugiadas. Sevilla, España. Recuperado de http:/ / www.juntadeandalucia.es/export/drupaljda/ asilo_proteccion_internacional.pdf

Organización de Estados Americanos -[OEA]. (1994). Convención Interamericana sobre Tráfico Internacional de Menores. México. Recuperado de http: / / www. oas.org/dil/esp/tratados_B-57_Convencion_Interamericana_sobre_Trafico_ Internacional_de_Menores.htm

Organización delos Estados Americanos-[OEA] (1994). Convención Interamericana para Prevenir, Sancionar y Erradicar la Violencia contra la Mujer o Convención de Belém do Pará. Brasil. Recuperado de http://www.oas.org/juridico/ spanish/firmas / a-61.html, también en http: / / apw.cancilleria.gov.co/ tratados / SitePages / VerTratados.aspx?IDT=50dee301-4bbb-4e43-ad54-be6105d5271a

Organización de Naciones Unidas -[ONU]. (s.f). Human Trafficking. Recuperado de http:/ / www.unodc.org/pdf/HT_GPATleaflet07_es.pdf y en https:/ / www. unodc.org/unodc/es / human-trafficking/index.html?ref=menuside

Organización de Naciones Unidas -[ONU]. (2009). Global Report on Trafficking in Persons. Recuperado de http://www.unodc.org/documents/humantrafficking/Global_Report_on_TIP.pdf

Organización de Naciones Unidas -[ONU]. (2009). Informe Mundial sobre la Trata de Personas. Resumen ejecutivo. Recuperado de http://www.unodc.org/ documents/human-trafficking/TIP_Executive_summaries.pdf 
Parlamento y Consejo de la Unión Europea. (2011). Directiva 2011/36/UE de 5 abril de 2011. Recuperado de http://eur-lex.europa.eu/LexUriServ/LexUriServ. do?uri=OJ:L:2011:101:0001:0011:Es:PDF

Pérez, E. (2008). Tráfico de Personas e Inmigración Clandestina: Un estudio sociológico, internacional y jurídico-penal. España: Tirant lo Blanch.

Ramírez, J. (2005). El Genoma y la División de Clases. Conversaciones con Jorge Halperín. Revista de Economía Institucional. 7(13). Recuperado de http:/ / www. scielo.org.co/scielo.php?script=sci_arttext\&pid=S0124-59962005000200017

Real Academia de la Lengua Española. Diccionario de la Lengua Española. (s. f.) Edición Tricentenario. Recuperado de http:/ / dle.rae.es / ?id=SjUIL8Z.

Reino de España. Real Decreto de 24 de julio de 1889. Por el que se publica el Código Civil. BOE No. 206. Ministerio de Gracia y Justicia, julio de 1889. Recuperado de https: / / www.boe.es/buscar/pdf/1889 / BOE-A-1889-4763-consolidado.pdf

Reino de España. Ley 20 de 2011, de Registro Civil. BOE No. 175. Jefatura de Estado, julio de 2011.

República del Perú. Decreto Legislativo 295 de 1984. Código Civil. Ministerio de Justicia y Derechos Humanos, julio de 1984. Recuperado de http:// spij.minjus.gob.pe / CLP / contenidos.dll? $\mathrm{f}=$ templates\&fn=default-codcivil. htm\&vid=Ciclope:CLPdemo

República del Perú. Sentencia 1486-2007 (2008, julio 18). Casación. Considerandos 17 y 18. Sala Civil Transitoria, Corte Suprema de Justicia.

Save the Children España. (2008). Conclusiones y aportaciones desde las instituciones y ONGs participantes. Trabajo presentado en el Congreso Internacional "Trata de Niños y Niñas. Cómo Promover la Identificación y la Protección de las Víctimas". Madrid. Recuperado de https://www. savethechildren.es/sites / default/files/imce/docs/trata_como_promover_la_ identificacion_y_la_proteccion_de_las_victimas_0.pdf

U. S. Departament of State-Departamento de Estado de EE.UU. (2011). Trafficking in Persons Report. Recuperado de http://www.state.gov/documents / organization/167348.pdf

U.S. Departament of State-Departamento de Estado de EE.UU. (2012, 2013, 2014 y 2015) Trafficking in Persons Report. Recuperado de http://www.state.gov/j/ tip/rls/tiprpt/; http://www.state.gov/documents/organization/192587. pdf; http:/ / www.state.gov/documents/organization/210737.pdf; http:/ / www.state.gov/ documents / organization/226844.pdf; http: / / www.state.gov/ documents/organization/245365.pdf;

Vela, J (2005). Orígenes de la Palabra Personalidad. Citas con el Psicólogo [Mensaje en un blog]. Recuperado de http://consultandoalpsicologo.blogspot.com. co/2014/09/ origenes-de-la-palabra-personalidad.html. 